\title{
The diagnostic value of circulating microRNAs in heart failure (Review)
}

\author{
YAO-MENG HUANG ${ }^{1}$, WEI-WEI LI ${ }^{1}, \mathrm{JUN}^{\mathrm{W}}{ }^{1}, \mathrm{MEI} \mathrm{HAN}^{1}$ and BING-HUI LI ${ }^{2}$ \\ ${ }^{1}$ Hebei Key Laboratory of Medical Biotechnology, Hebei Medical University, Shijiazhuang, Hebei 050017; \\ ${ }^{2}$ Department of Oncological Surgery, Fourth Hospital of Hebei Medical University, \\ Shijiazhuang, Hebei 050011, P.R. China
}

Received July 8, 2018; Accepted January 7, 2019

DOI: $10.3892 /$ etm.2019.7177

\begin{abstract}
Heart failure (HF) is a complex clinical syndrome, characterized by inadequate blood perfusion of tissues and organs caused by decreased heart ejection capacity resulting from structural or functional cardiac disorders. HF is the most severe heart condition and it severely compromises human health; thus, its early diagnosis and effective management are crucial. However, given the lack of satisfactory sensitivity and specificity of the currently available biomarkers, the majority of patients with HF are not diagnosed early and do not receive timely treatment. A number of studies have demonstrated that peripheral blood circulating nucleic acids [such as microRNAs (miRs), mRNA and DNA] are important for the diagnosis and monitoring of treatment response in $\mathrm{HF}$. miRs have been attracting increasing attention as promising biomarkers, given their presence in body fluids and relative structural stability under diverse conditions of sampling. The aim of the present review was to analyze the associations between the mechanisms underlying the development of $\mathrm{HF}$ and the expression of miRs, and discuss the value of using circulating miRs as diagnostic biomarkers in HF management. In particular, miR-155, miR-22 and miR-133 appear to be promising for the diagnosis, prognosis and management of HF patients.
\end{abstract}

Correspondence to: Professor Mei Han, Hebei Key Laboratory of Medical Biotechnology, Hebei Medical University, 361 Zhongdong Road, Shijiazhuang, Hebei 050017, P.R. China

E-mail: hanmei@hebmu.edu.cn

Professor Bing-Hui Li, Department of Oncological Surgery, Fourth Hospital of Hebei Medical University, 12 Health Road, Shijiazhuang, Hebei 050011, P.R. China

E-mail: 1bh58@hebmu.edu.cn

Key words: circulating microRNAs, heart failure, diagnostic biomarkers

\section{Contents}

1. Introduction

2. Changes and associated mechanisms of miRs in various types of HF

3. Circulating miRs as diagnostic biomarkers

4. Conclusion

\section{Introduction}

The causes of heart failure (HF) include ischemic cardiomyopathy (ICM) and dilated cardiomyopathy (DCM), hypertension, valvular heart disease, diabetic cardiomyopathy and congenital heart disease (CHD) (1). The pathogenesis of HF is associated with myocardial hypertrophy, fibrosis or necrosis, cardiomyocyte apoptosis, renin-angiotensin-aldosterone system imbalance and collagen changes, as well as several other factors (2-7).

MicroRNAs (miRs) are small ( 22 nucleotides in length), single-strand, non-coding RNA sequences derived from precursors that control gene expression in a variety of physiological and developmental processes, which are involved in post-transcriptional regulation of gene expression (8). miR disorders are associated with a number of human diseases, including diabetes, myocardial infarction and cardiovascular disease, obesity and cancer. Several studies have demonstrated that miRs may affect different aspects of the occurrence and development of HF (9-14). The association between miRs and HF is discussed in detail below.

Circulating miRs are increasingly recognized as promising biomarkers, given their stability and resistance to endogenous RNase (15); these miRs, to some degree, may also be used as diagnostic biomarkers for angiocardiopathy. In addition, miRNAs and various types of HF have complex relationships, as described below.

\section{Changes and associated mechanisms of miRs in various types of HF}

miRs may be involved in several aspects of the occurrence and development of HF, such as cardiomyocyte apoptosis, hypertrophy, fibrosis, inflammation, oxidative damage and 
hypoxic damage (9-14), among others. The specific regulatory functions of miRs are indicated in Figs. 1 and 2 and are summarized in Table I (16-66).

\section{Circulating miRs as diagnostic biomarkers}

HF is primarily caused by cardiomyopathy, hypertension, diabetes and CHD, among other causes (15). The different etiology is associated with several miRs.

miRs associated with cardiomyopathy. The cardiomyopathies leading to HF predominantly include DCM and ICM (67-71). DCM, characterized by left ventricular dilatation, ventricular wall thinning and diffuse myocardial dysfunction, leads to congestive HF (72) and right ventricular dysfunction (73). These pathological changes result in the transition from compensatory hypertrophy to DCM (74). The heart undergoes continuous remodeling of myocardial cells through transduction of intercellular signals and activation of the transcription and transmission pathways (75). Naga Prasad et al (76) performed reverse transcription-quantitative polymerase chain reaction (RT-qPCR) analysis on a set of samples used for miR microarray analysis, and identified that hsa-mir-378 $(\mathrm{P}<0.0055)$, hsa-mir-001 $(\mathrm{P}<0.0001)$, hsa-mir-007 $(\mathrm{P}<0.0009)$ and hsa-mir-29b $(\mathrm{P}<0.0087)$ were notably decreased in DCM compared with control samples; by contrast, hsa-mir-342 ( $\mathrm{P}<0.0004)$, hsa-mir-214 $(\mathrm{P}<0.0001)$, hsa-mir-125b $(\mathrm{P}<0.0785)$, hsa-mir-145 $(\mathrm{P}<0.0091)$ and hsa-mir-181b $(\mathrm{P}<0.0047)$ were significantly increased in DCM compared with non-failing controls, and may be used to indicate the stage of HF development. Enes Coşkun et al (77) investigated 23 pediatric patients (aged 2-192 months) with isolated idiopathic DCM as the experimental group, and 26 age-matched healthy children with innocent murmur as the control group. Patients with fractional shortening of $<25 \%$ and with a left ventricular end-diastolic diameter $>112 \%$ of the predicted dimension were considered to have DCM. The results of RT-qPCR demonstrated that the expression levels of miR-454 and miR-518f were significantly higher in DCM patients compared with those in the control group. Furthermore, the expression levels of $10 \mathrm{miRs}$ (miR-618, miR-875-3p, miR-205, miR-194, miR-302a, miR-147, miR-544, has-miR-99b, miR-155 and miR-218) were notably lower in patients with DCM compared with control subjects, suggesting that they may be used as potential diagnostic biomarkers. Interestingly, Miyamoto et al (78) observed that 2 miRs (hsa-miR-636 and hsa-miR-155) were upregulated and 2 miRNAs (hsa-miR-646 and hsa-miR-639) were downregulated in patients with DCM compared with patients with DCM with recovered ventricular function, which indicated that they may serve as diagnostic as well as prognostic biomarkers. However, further research is required to elucidate the specific underlying mechanisms.

Leger et al (79) and Zeng et al (80) measured left ventricular ejection fraction (LVEF) and the 6-min walk test distance (6MWTD) and CBP/p300 interacting transactivators with ED-rich termini 2 (CITED2), hypoxia-inducible factor-1 (HIF-1) in patients with ICM before and after treatment, and identified that LVEF, 6MWTD, CITED2 and HIF-1 levels were significantly lower in the ICM group compared with those in the control group prior to treatment $(\mathrm{P}<0.01)$. The $\mathrm{N}$-terminal pro-B-type natriuretic peptide (NT-proBNP), HIF-1 and miR-182 levels in the ICM group were significantly higher compared with those in the control group $(\mathrm{P}<0.01)$. Following 4 months of treatment, the levels of 6MWTD, CITED2 and LVEF in the ICM group were significantly increased, whereas the levels of plasma NT-proBNP, HIF-1 and miR-182 were significantly decreased $(\mathrm{P}<0.01)$. Furthermore, the plasma miR-182 level was negatively correlated with CITED2, LVEF and 6MWTD $(\mathrm{P}<0.05)$ and positively correlated with HIF-1 $(\mathrm{P}<0.05)$ in the ICM group. Therefore, miR-182 is correlated with several indicators of HF, and may be considered to reflect the severity of the disease. Olson and Rooij (81) and Fichtlscherer et al (82) observed upregulation of miR-208a and miR-499 and downregulation of the circulating levels of miR-126, miR-17, miR-92a and the inflammation-associated miR-155 in patients with coronary artery disease compared with healthy controls by qPCR. Similarly, the level of miR-145 in smooth muscle was significantly reduced. By contrast, the levels of cardiac muscle-enriched miRs (miR-133a and miR-208a) tended to be higher in patients with coronary artery disease. Li et al (83) demonstrated a decrease of miR-125a, miR-20a and miR-302d levels in ICM using Deep RNA sequencing. Notably, only 55 miRs were indicated to be consistently increased in ICM and non-ischemic cardiomyopathy (NICM), including miR-21-5p, miR-125b-1-3p and miR-106b-5p, among others. However, 38 miRNAs were downregulated in both ICM and NICM (non-ischemic cardiomyopathy), including miR-20a-5p, miR-17-5p and let-7e-5 (83). The findings suggest that miR-182 appears to be a promising new biomarker for the diagnosis of ICM and DCM in clinical research.

miRs associated with hypertension. Hypertension is an independent risk factor for cardiac and cerebrovascular disease (84). It has been reported that at least $50 \%$ of patients with long-term hypertension will likely undergo cardiac remodeling, particularly left ventricular remodeling (85). Myocardial cell hypertrophy is among the primary causes underlying the occurrence of HF (86). Notably, it has been demonstrated that miR-208 can induce cardiac hypertrophy and results in the overexpression of $\beta$-myosin heavy chain in myocardial fibrosis (87). Several miRs were indicated to be differentially expressed in hypertension, including miR-296-5p, let-7e and human cytomegalovirus (HCMV)-miR-UL112, as encoded by HCMV in previous studies of the hypertension-associated miR spectrum (88-90). Interferon regulatory factor 1 , which is involved in the regulation of blood pressure by acting on nitric oxide synthase and vascular angiotensin (Ang) receptor, was demonstrated to be a direct target of HCMV-miR-UL112 (91). However, in hypertension, HCMV titers are considered to reflect the expression level of HCMV-miR-UL 112 (91), which is an independent risk factor for hypertension. HCMV has been reported to inhibit vasodilation by impairing nitric oxide synthase function (92) and causing endothelial cell dysfunction (93). However, further research is warranted due to the elusive association between HCMV infection and endothelial dysfunction. 


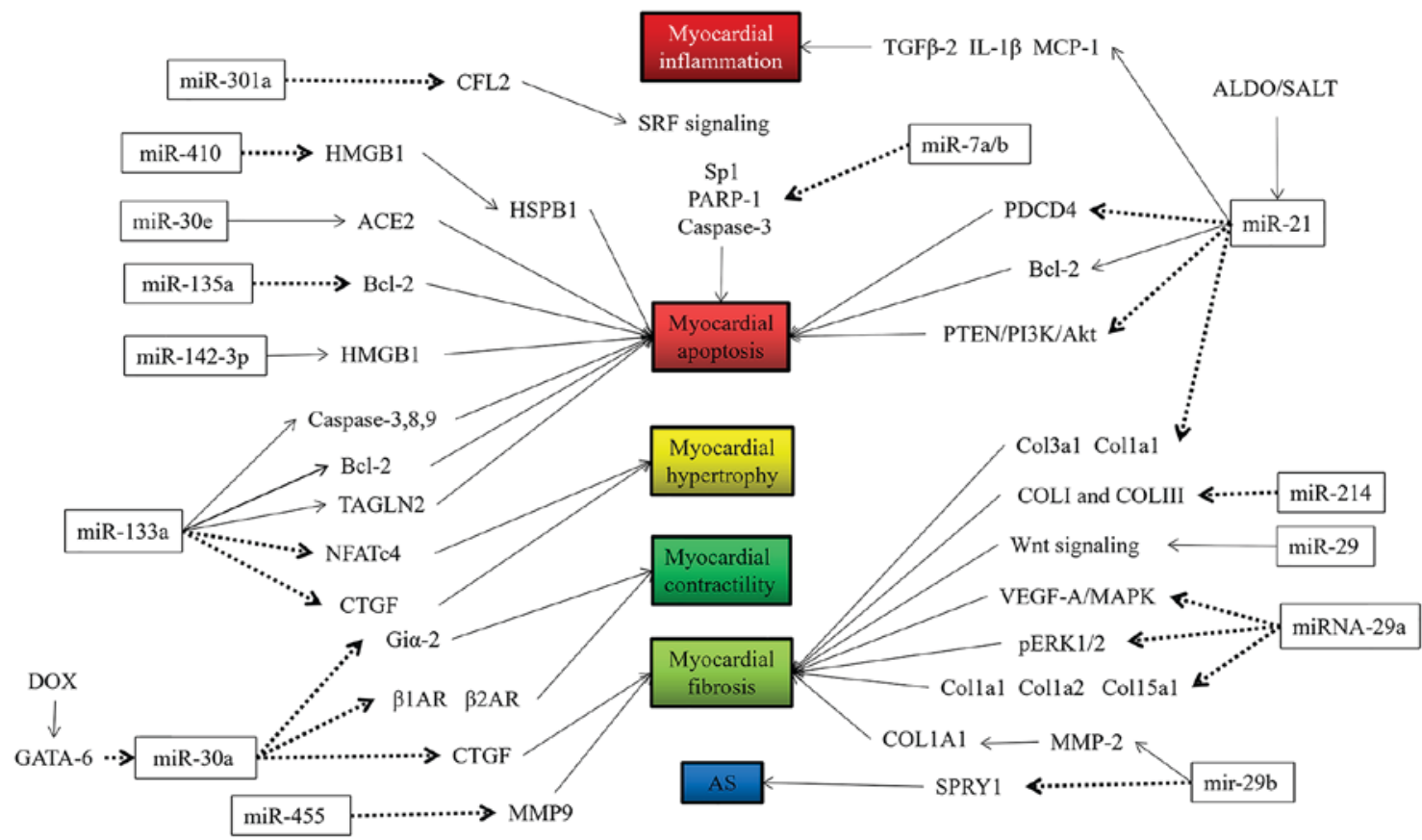

Figure 1. Association between miRs and different pathogenic mechanisms of heart failure. Solid lines represent positive regulation and dashed lines represent negative regulation. The nock of the arrow controls the tip of the arrow, for example miR-7a/b downregulates Sp1, PARP-1 and caspase-3, whereas Sp1, PARP-1 and caspase-3 promote myocardial fibrosis. Therefore, miR-7a/b protects cardiomyocytes against apoptosis. CFL2, Cofilin-2; HMGB1, high-mobility group box 1 protein; HSBP1, Heat Shock Factor Binding Protein 1; ACE2, Angiotensin-convertingenzyme2; Bcl-2, B-cell lymphoma-2; SRF, serum response factor; TAGLN2, Transgelin 2; NFATC4, Nuclear Factor Of Activated T Cells; CTGF, connective tissue growth factor; DOX, Doxorubicin; MMP-9, matrix metalloproteinase-9; $\beta 1 \mathrm{AR}$ and $\beta 2 \mathrm{AR}, \beta 1$-and $\beta 2$-adrenoceptor; TGF- $\beta$, transforming growth factor- $\beta$; IL-1 $\beta$, Interleukin- $1 \beta$; MCP1, monocyte chemoattractant protein-1; PDCD4, programmed cell death 4; SP1, specific protein 1; PARP1, poly ADP-ribose polymerase; ALDO, aldosterone; PTEN, phosphatase and tensin homolog deleted on chromosome 10; PI3K, phosphatidylinositol-4,5-bisphosphate 3-kinase; Akt, Protein Kinase B; Col1a1, collagen 1A1; Colla2, collagen 1A2; col15a1, collagen 15A1; Col III, type III collagen; Col I, type I collagen; MAPK, mitogen-activated protein kinase; VEGF, Vascular endothelial growth Factor; ERK, extracellular regulated protein kinases; MMP-2, matrix metalloproteinase-2; SPRY1, Protein sprouty homolog 1.

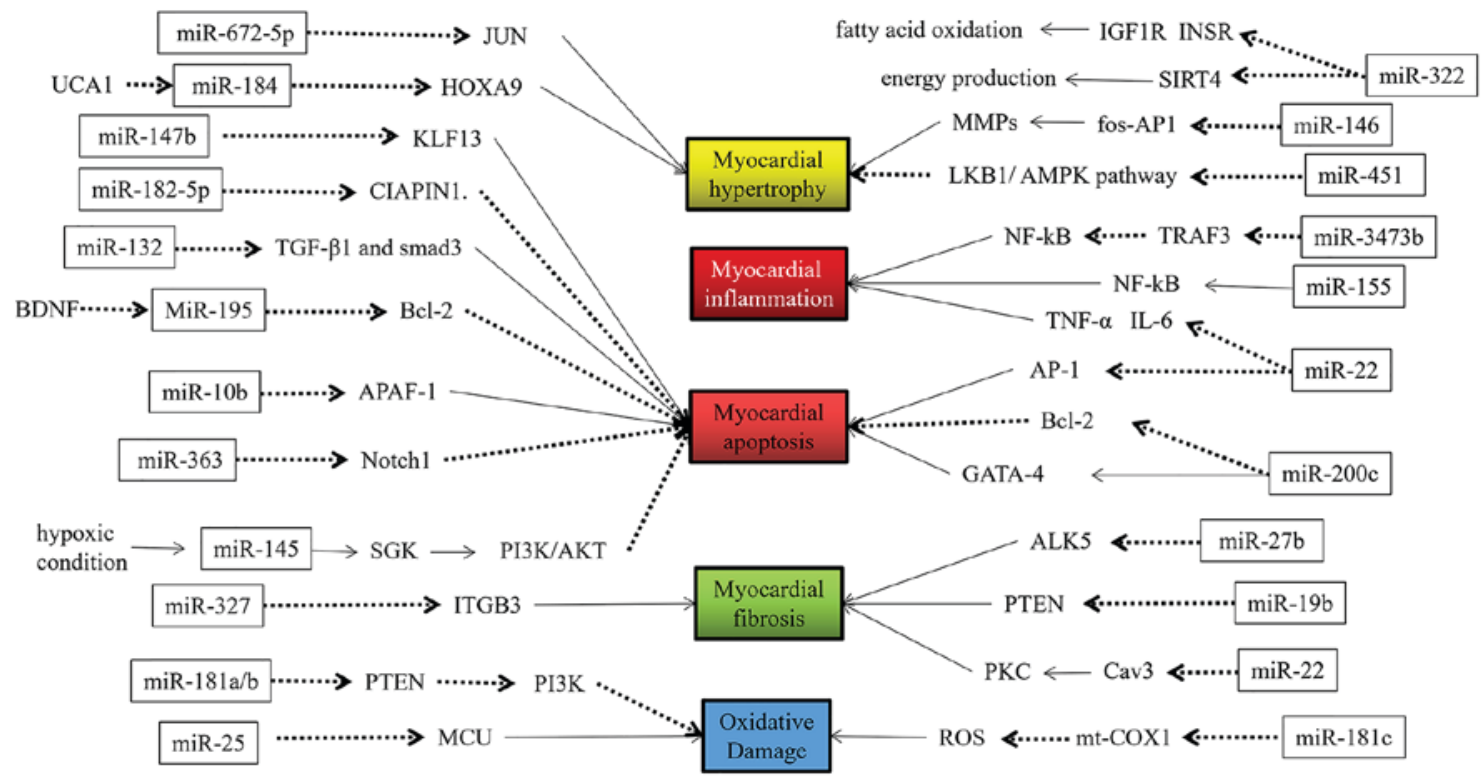

Figure 2. Association between miRs and different pathogenic mechanisms of heart failure. Solid lines represent positive regulation and dashed lines represent negative regulation. The nock of the arrow controls the tip of the arrow, for example miR-451 downregulates the LKB1/AMPK pathway, and the LKB1/AMPK pathway negatively regulates the tendency for cardiomyocyte hypertrophy. Therefore, miR-451 promotes myocardial hypertrophy. JUN, Jun proto-oncogene product which is a subunit of the AP-1 transcription; HOXA9, Homeobox A9; UCA1, urothelial carcinoma-associated 1; KLF13, Kruppel-like transcription factor 13; CIAPIN1, cytokine-induced anti-apoptotic molecule; BDNF, brain derived neurotrophic factor; TGF $\beta-1$, transforming growth factor $\beta$-1; Bcl-2, B-cell lymphoma-2; APAF-1, apoptotic protease activating factor-1; SGK, Serum and Glucocorticoid Induced Kinase; PI3K, phosphatidylinositol-4,5-bisphosphate 3-kinase; ITGB3, integrin $\beta 3$; PTEN, phosphatase and tensin homolog deleted on chromosome 10; MCU, mitochondrial calcium uptake; INSR, insulin receptor; IGFR1, Insulin-like growth factor 1 receptor; SIRT4, Sirtuin-4; fos-AP1, Fos-Associated Protein 1; MMP, matrix metalloproteinase; AMPK, adenosine monophosphate-activated protein kinase; LKB1, Liver kinase B1; NF-кB, nuclear factor kappaB; TRAF3, TNF receptor associated factor 3; TNF- $\alpha$, tumor necrosis factor- $\alpha$; IL-6, interleukin-6; AP-1, activator protein-1; ALK-5, activin-like kinase 5; PKC, protein kinase C; CAV3, Caveolin 3; ROS, reactive oxygen species; COX, cycloxygenase. 


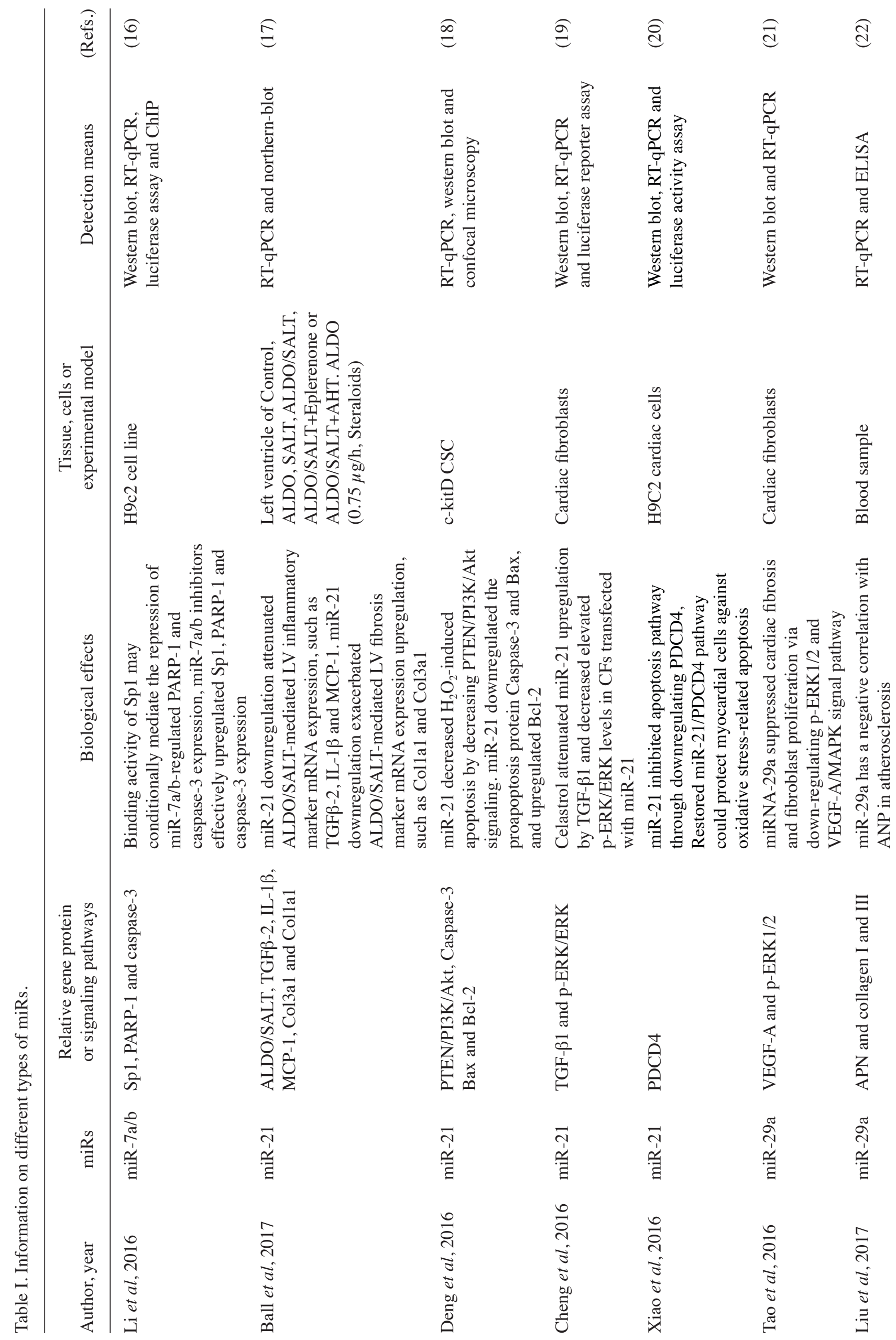




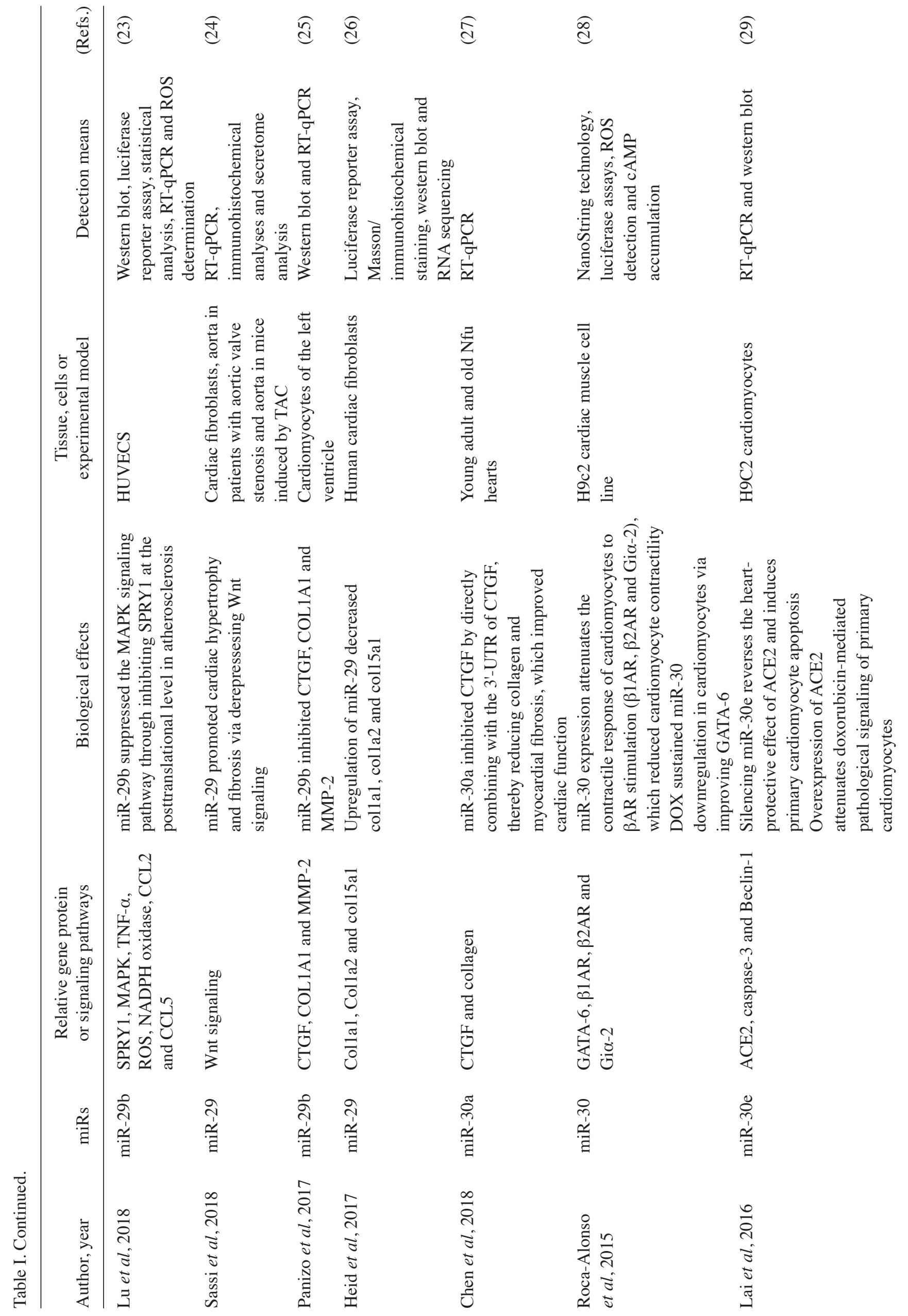




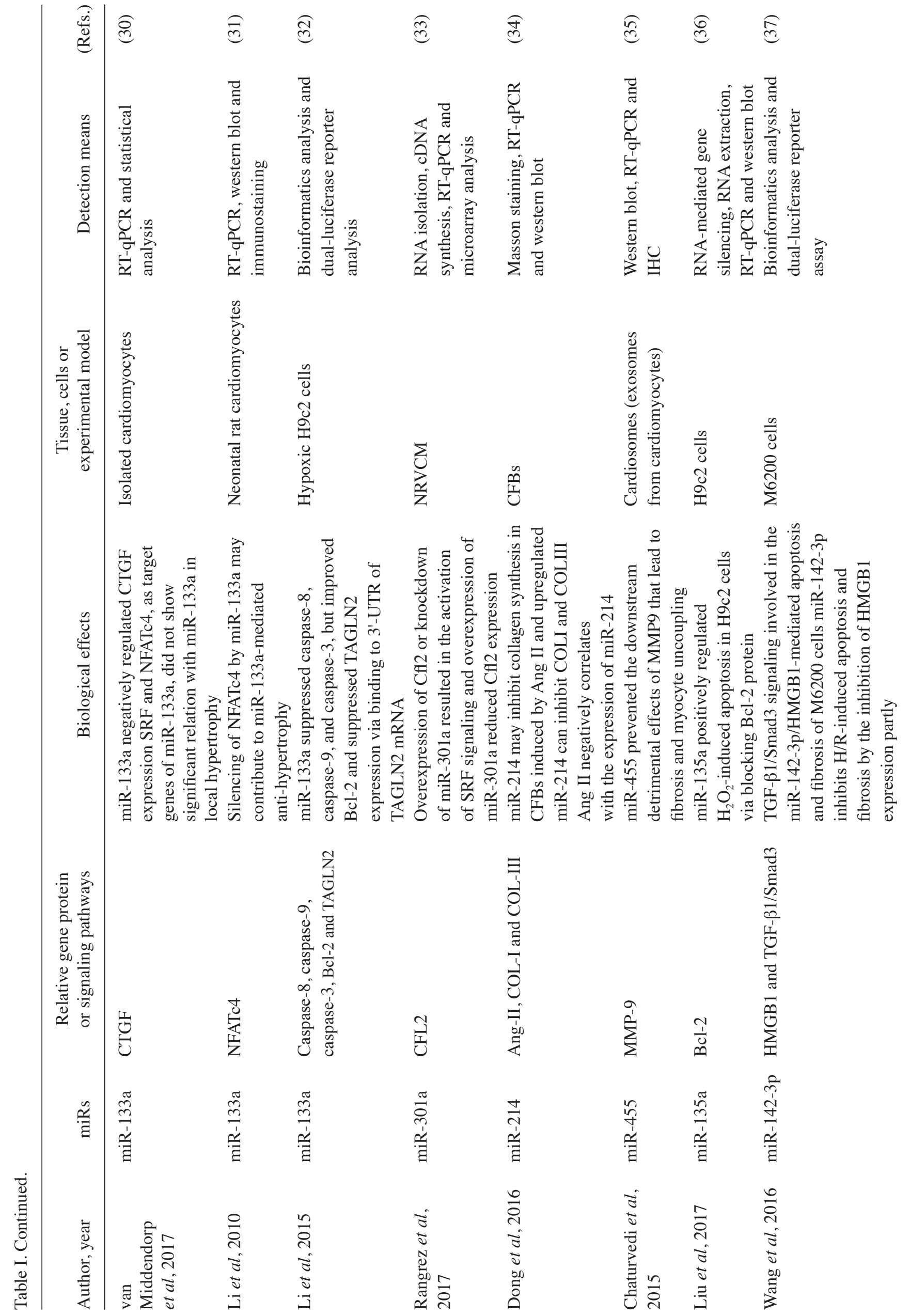




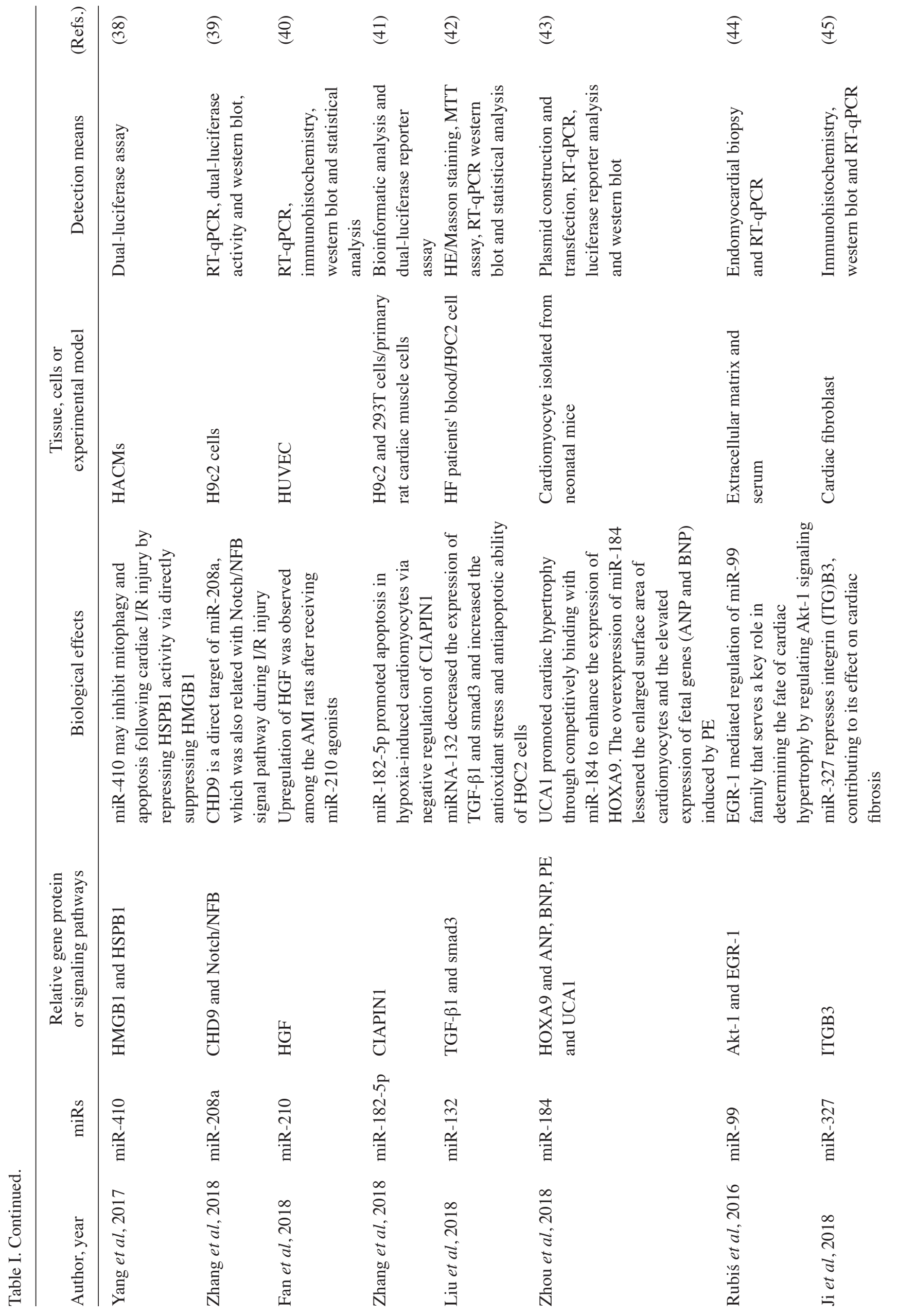




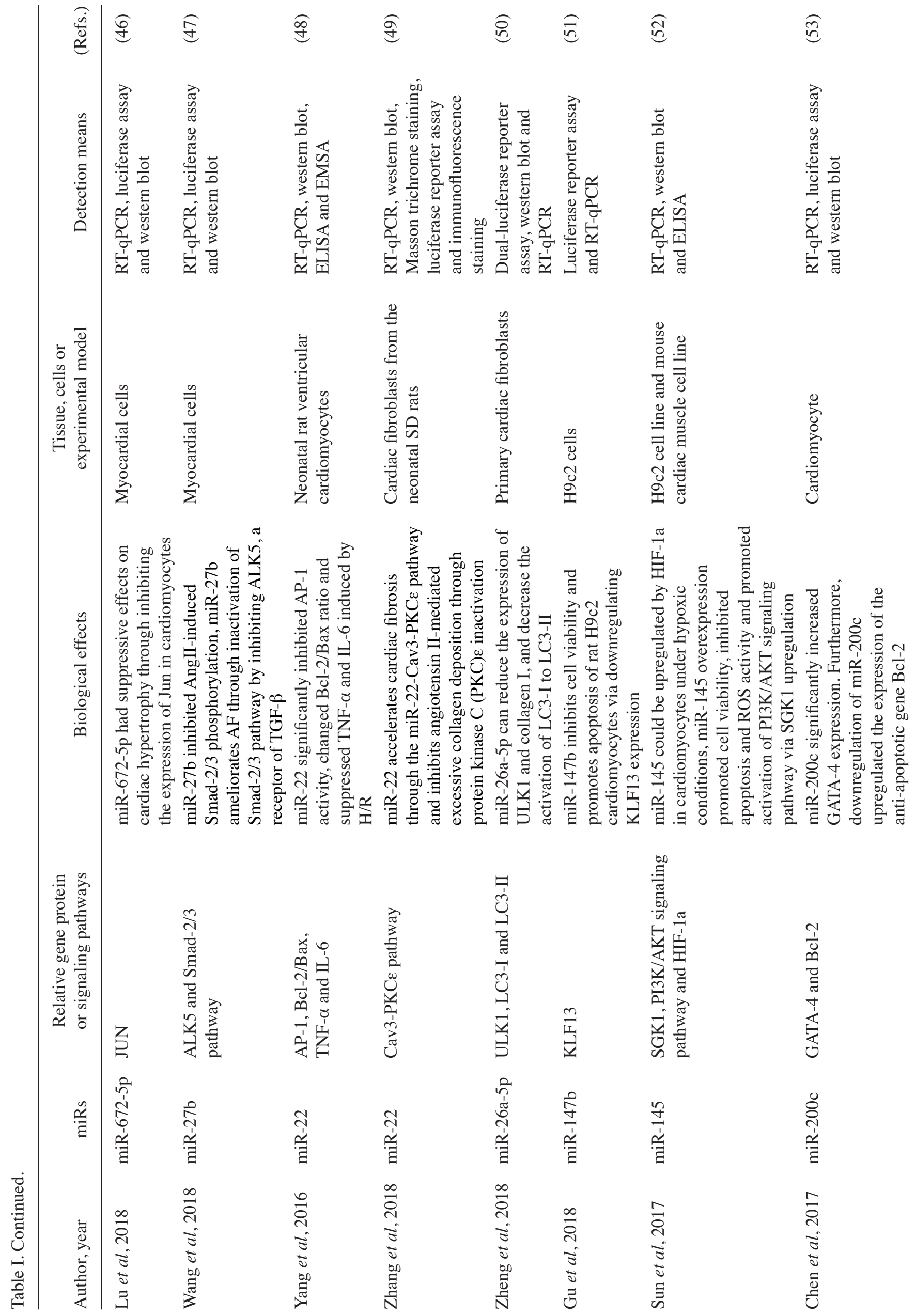




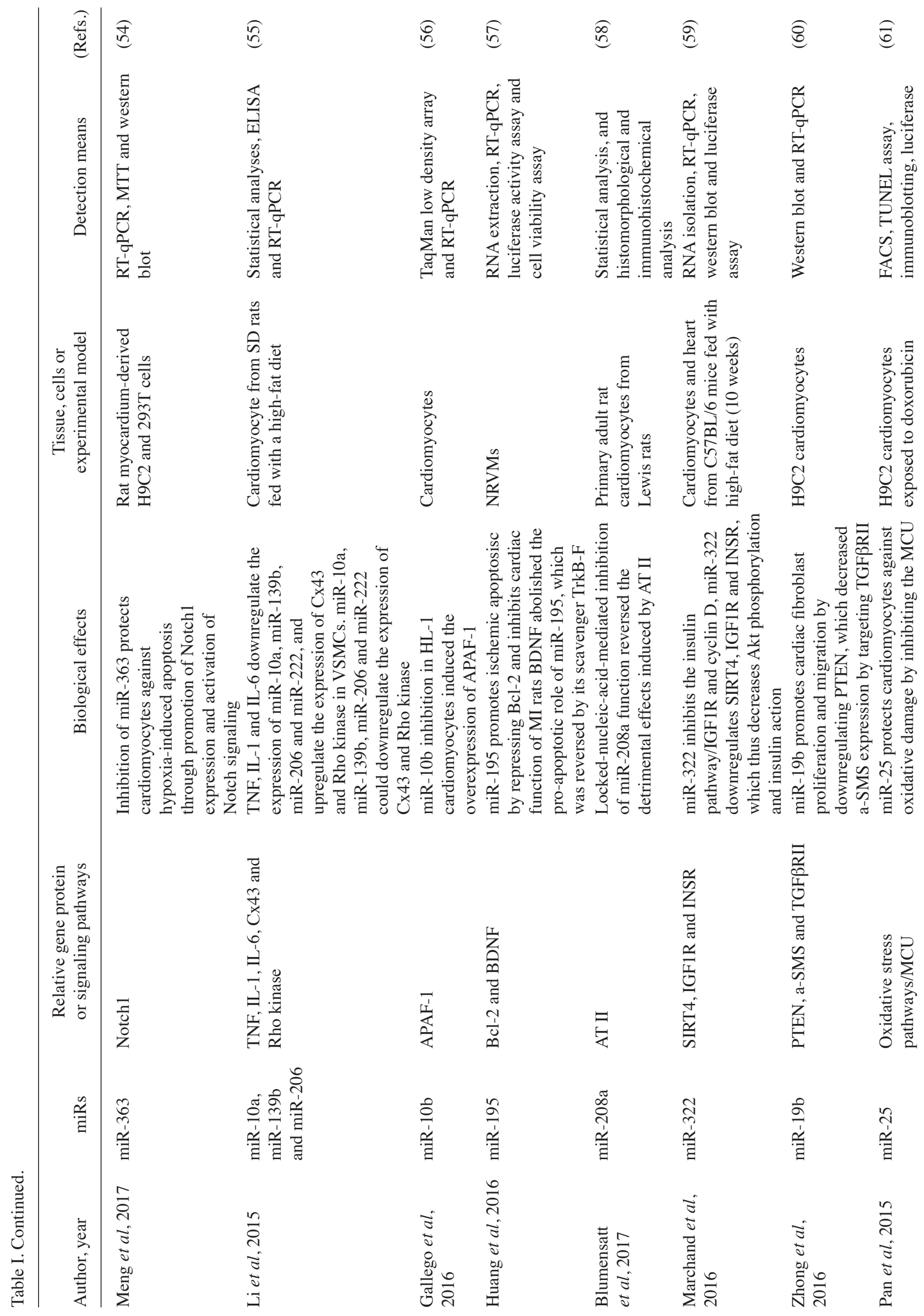




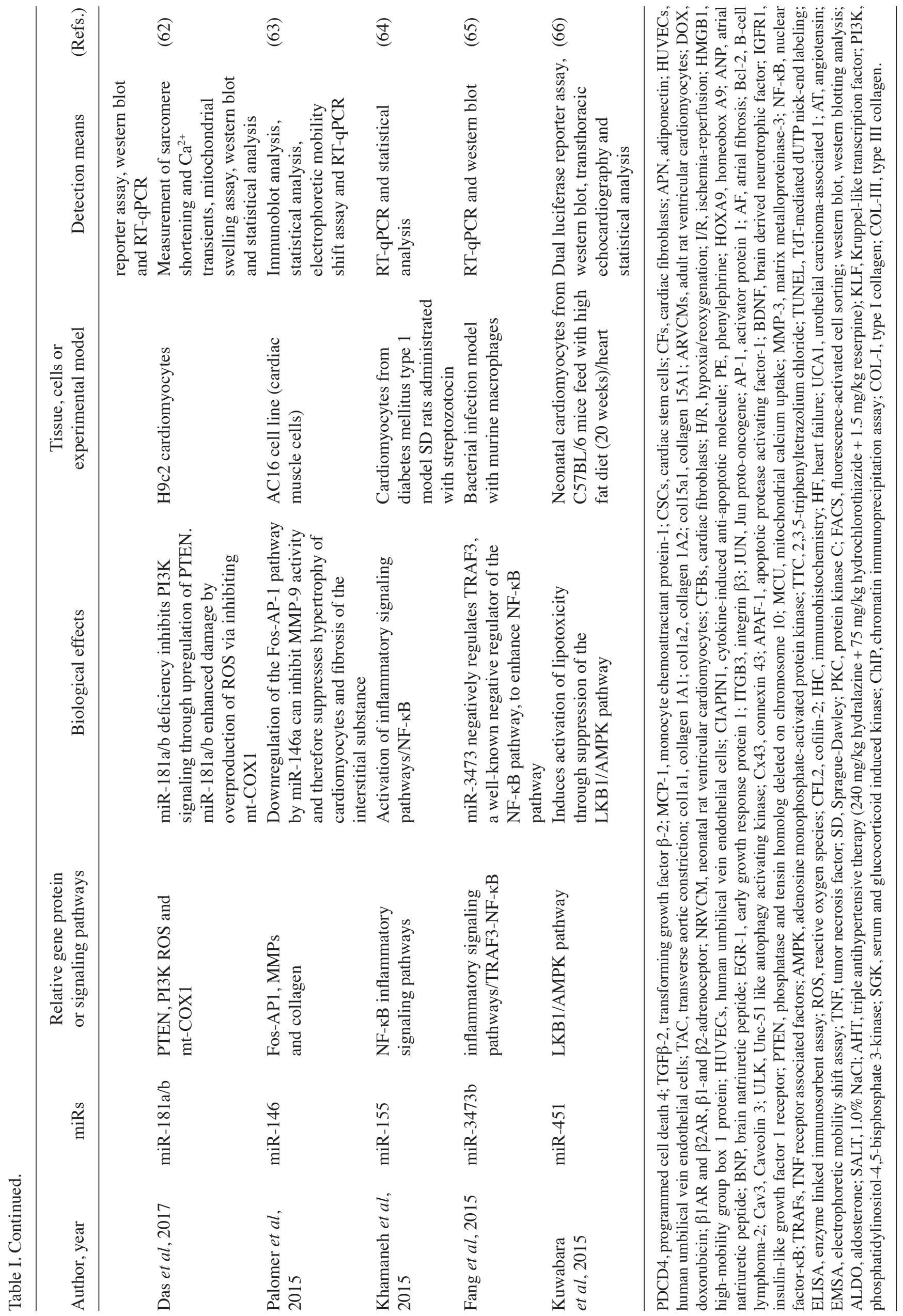


Kontaraki et al $(94,95)$ reported that upregulated miRs included miR-1 and miR-21, whereas downregulated miRs included miR-9, miR-126, miR-133, miR-143 and miR-145 in the hypertension group compared with the healthy control group. In addition, miR-21, miR-143 and miR-145 were negatively correlated and miR-133 was positively correlated with 24-h ambulatory mean blood pressure, mean diastolic blood pressure and mean pulse pressure in the hypertension group. Furthermore, miR-9 and miR-126 were positively correlated with mean pulse pressure, but the association between miR-9 and left ventricular hypertrophy index was positively correlated with the 24-h ambulatory mean blood pressure and mean diastolic blood pressure. Therefore, this miR may reflect the severity of hypertensive HF.

Dickinson et al (96) reported that the circulating levels of miR-423-5p, miR-106b, miR-20b, miR-223, miR-16 and miR-93 were markedly increased in hypertension-induced HF, which was confirmed via RT-qPCR analysis of plasma RNA from hypertensive rats. These results indicate that several miRs can reflect disease progression to a certain extent, and may be used as biomarkers of hypertensive HF. This suggests that miRs should be detected pre- and post-treatment to reduce the effects of medication on the results of the experiment. Hou et al (97) randomly divided 16 spontaneously hypertensive rats (SHR) into the SHR control (distilled water) and intervention SHR (captopril $10 \mathrm{mg} / \mathrm{kg} /$ day) groups. An additional $8 \mathrm{Wistar}$ male rats comprised the normal control groups (captopril $10 \mathrm{mg} / \mathrm{kg} / \mathrm{day}$ or distilled water for 8 weeks). The expression of miR-137 was detected by RT-qPCR and western blot analysis in rat hearts, and miR-137, Ang II, transforming growth factor (TGF)- $\beta 1$, Smad3, collagen (Col)-I and Col-III were identified to be more highly expressed in the SHR treatment and SHR control groups than the normal control group $(\mathrm{P}<0.01$ and $\mathrm{P}<0.05$, respectively); by contrast, the levels of miR-137, Ang II, TGF- $\beta 1$, Smad3, Col-I and Col-III were significantly lower in the normal control groups compared with the SHR control group $(\mathrm{P}<0.01$ and $\mathrm{P}<0.05$, respectively). Thus, miR-137 may promote cardiac remodeling in SHR by upregulation of Ang II and the TGF- $\beta 1 / \mathrm{Smad} 3$ signaling pathway; in addition, captopril intervention can inhibit miR-137 expression. Therefore, miR-137 not only indicates the presence of high blood pressure, it may also reflect its severity.

Li et al (98) reported that insulin-like growth factor (IGF)-1 prevented diabetes-induced cardiomyopathy via marked anti-apoptotic and anti-fibrotic effects, which are mediated by miR-1. These findings provide a new paradigm for the endocrine effects of IGF-1 in the heart, and suggest that cardiac-specific miR-1 may be a useful biomarker and therapeutic target for diabetes-induced cardiomyopathy. Yang et al (99) observed that miR-505 interfered with the migration of cultured endothelial cells through targeting fibroblast growth factor 18, suggesting that miR-505 may be involved in vascular regeneration. In addition, a group of miRs (miR-92a, miR-130a and miR-195) were demonstrated to be abnormally expressed in hypertensive patients with metabolic syndrome. Notably, miR-92a is differentially expressed in the blood of hypertensive and non-hypertensive patients (100) and may promote miR-mediated intercellular communication (101). Kontaraki et al $(94,95)$ confirmed several types of differentially expressed miRs in an animal model: Myocardial hypertrophy was induced by miR-21, miR-208b and miR-499; the anti-myocardial hypertrophy miRs comprised miR-1, miR-26b and miR-133a, of which miR-1, miR-21, miR-208b and miR-499 were upregulated, whereas miR-26b and miR-133a were downregulated in peripheral blood mononuclear cells from patients with hypertension compared with healthy controls. In patients with hypertension, the degree of left ventricular hypertrophy was negatively correlated with the miR-1 and miR-133 indices, whereas the miR-21, miR-26b, miR-208b and miR-499 indices were positively associated with left ventricular hypertrophy.

miRs associated with diabetic HF. Dickstein (102) reported that the occurrence and development of insulin resistance in HF was correlated with overactivation of the renin-angiotensin-aldosterone system $(103,104)$, disturbance of energy metabolism in the myocardium (105), liver pathology, as well as other factors. It was previously demonstrated that the expression of miR-133 and miR-1 increased significantly in myocardial cells following hyperglycemic injury (106). IGF-1 and IGF-1 receptor are the two target genes of miR-1 (107). Previous studies demonstrated an increasing level of miR-133 and decreasing levels of miR-650, miR-222 and miR-338 in hyperglycemic cardiomyocyte injury $(108,109)$. Greco et al (110) collected biopsies from the peri-infarctual area (border zone) and the non-ischemic remote zone from patients with diabetic HF (D-HF), non-diabetic HF (ND-HF) and the control group. miR expression was measured using RT-qPCR in left ventricular biopsies from 10 patients with D-HF and 19 patients with ND-HF affected by non-end-stage ischemic cardiomyopathy. A total of $17 \mathrm{miRs}$ were revealed to be differentially expressed in patients with D-HF and/or ND-HF when compared with control subjects; in particular, miR-34b, miR-34c, miR-210, miR-199b and miR-372 were upregulated, whereas miR-650 and miR-223 were downregulated. Therefore, miRs may not only be obtained from the blood or serum, but also from tissue biopsies, when the content in the body fluids is low. Nandi et al (111) and Deng et al (112) reported that attenuation of miR-133a in diabetic hearts is associated with the induction of autophagy and hypertrophy. In conclusion, attenuation of miR-133a appears to serve a key role in $\mathrm{D}-\mathrm{HF}$ and contributes to the exacerbation of diabetes-mediated cardiac autophagy and hypertrophy in patients with HF undergoing left ventricular assist device implantation. Chavali et al (113) used multiplex RT-qPCR in insulin 2 mutant Akita mouse hearts (a diabetic mouse model with heart disease) and observed marked downregulation of miR-744, miR-142-3p, miR-384-3p, miR-494, let-7a, miR-450, miR-338, miR-130, miR-142-3p, miR-148, miR-338, miR-345-3p, miR-433, miR-451, miR-455, miR-500, miR-542-3p and miR-872. By contrast, miR-295 was upregulated in Akita mouse hearts. Therefore, miR-295 may be used as a mammalian-specific miR in early embryonic stages. Increased miR-295 expression was associated with pathological changes in Akita mouse hearts. miR-223, as an anti-inflammatory miR, may reflect the progression of diabetic Ins $2^{+/-}$Akita heart 


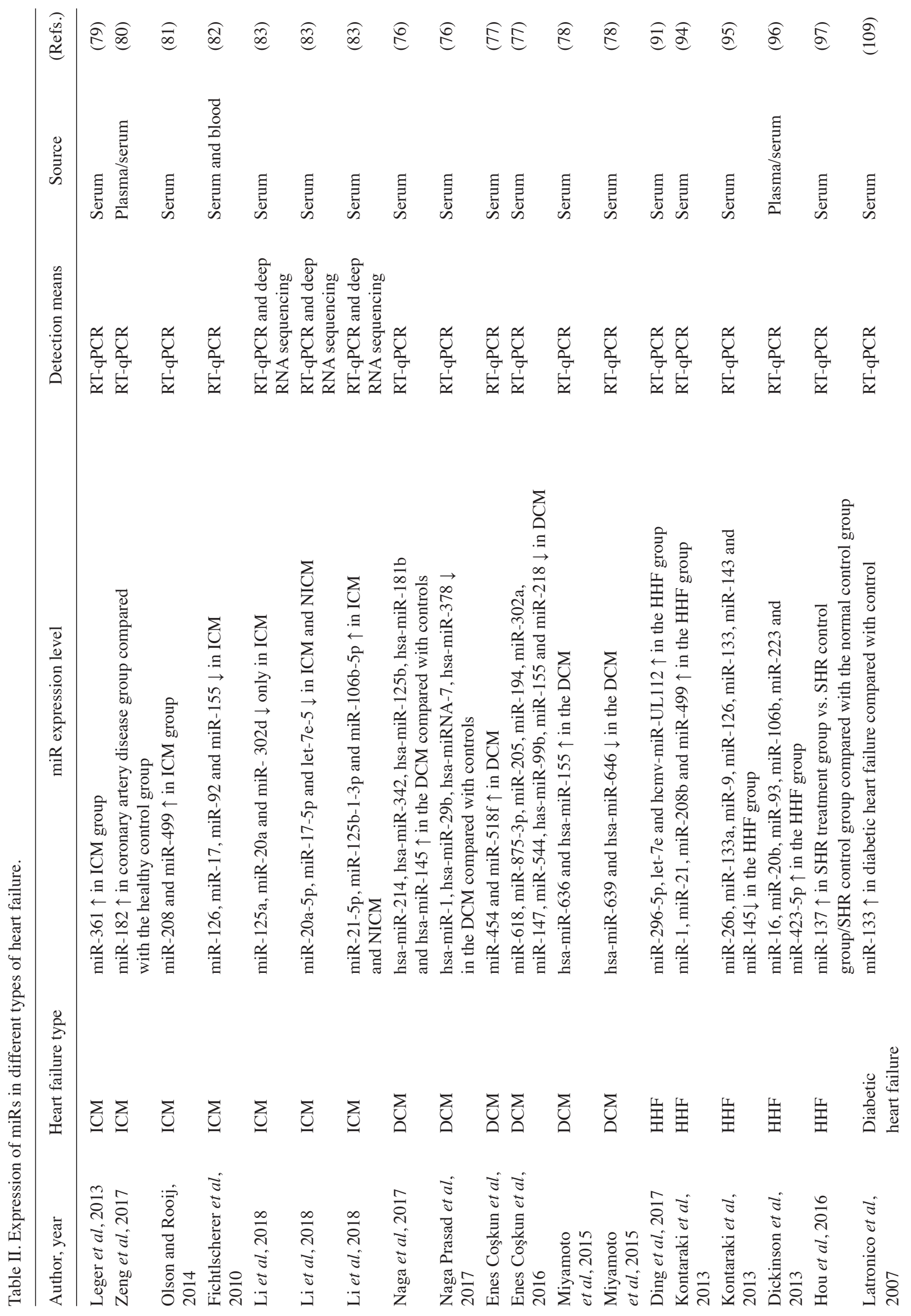




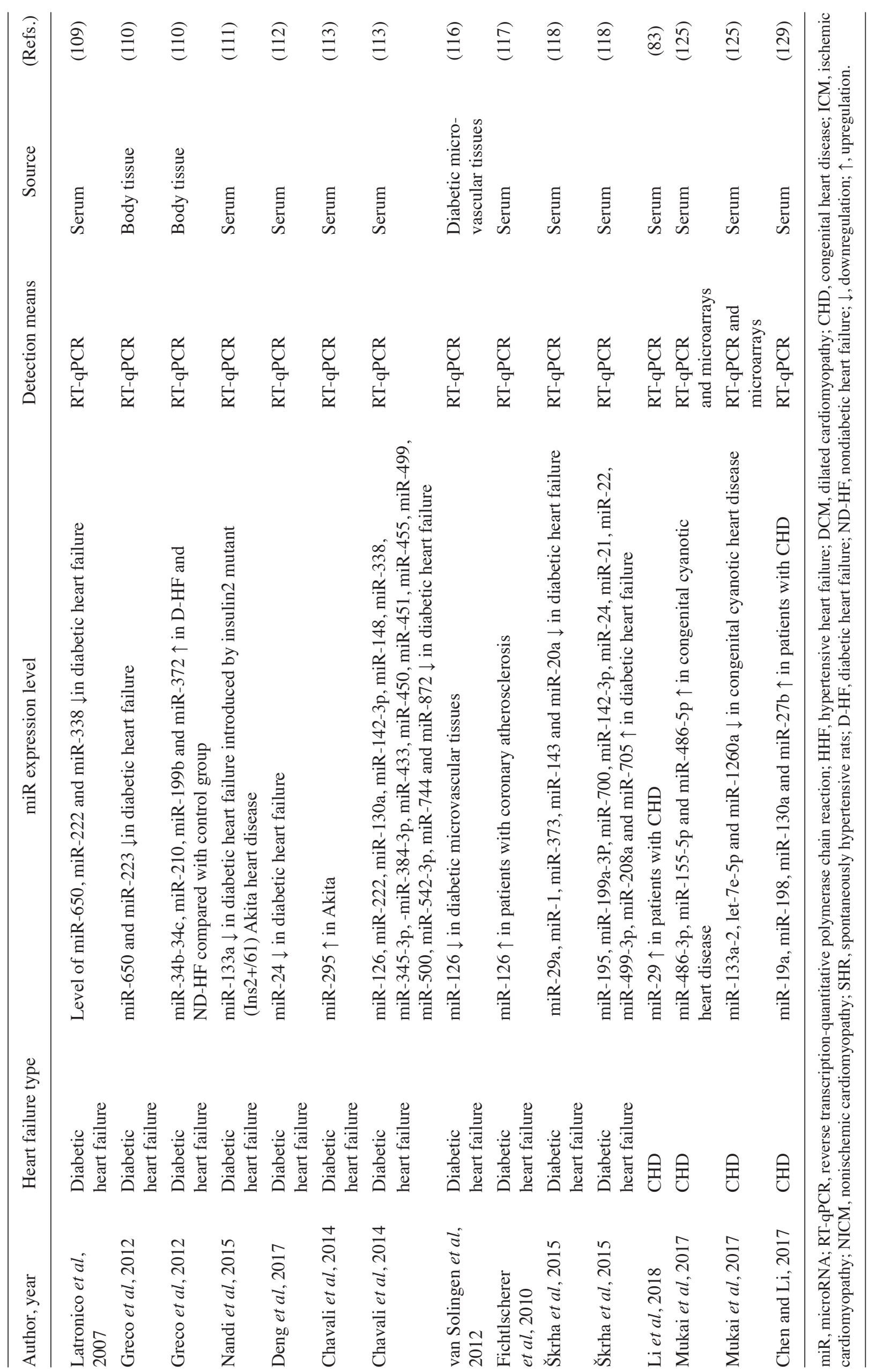


disease or D-HF. In another study, miR-1 and miR-133A were demonstrated to act as regulators of glucose homeostasis in vitro (113). Notably, miR-133a/b can reduce the expression of glucose transporter 4 and inhibit the uptake of glucose by insulin-induced myocardial cells (114). Furthermore, miR-133a/b targets Kruppel-like transcription factor 15 , which is directly involved in this process (108). Two other target genes of miR-133a/b are the human ether-a-go-go-related gene and KCNQI, and these two genes are involved in the regulation of cardiac $\mathrm{K}^{+}$ channels and the presence of long QT syndrome in patients with diabetes (115). The decrease of miR-126 in diabetic microvascular tissues may indicate the severity of diabetic vascular complications (116); however, the expression of miR-126 did not decrease, but was rather significantly increased in patients with coronary atherosclerosis (117). In a mouse model of type 1 diabetes mellitus established by streptozotocin (118), 15 miRs were differentially expressed in the myocardium, among which $10 \mathrm{miRs}$ (miR-195, miR-199a-3P, miR-700, miR-142-3p, miR-24, miR-21, miR-22, miR-499-3p, miR-208a and miR-705) were upregulated, whereas 5 miRs (miR-29a, miR-1, miR-373, miR-143 and miR-20a) were notably downregulated. Histological examination revealed hypertrophy of the myocardial cells in type 1 diabetes mellitus group mice compared with the control group, with a disorderly arrangement and enlarged nuclei. Notably, the prediction of associated target genes primarily involves cell growth, differentiation, proliferation, collagen fiber growth, apoptosis and angiogenesis.

miRs of HF in CHD. CHD is a multi-gene genetic disease resulting from structural or functional cardiovascular abnormalities present at birth that are caused by congenital abnormalities (119). Disrupted miR expression may result in CHD via specific protein regulation. miR-133 and miR-1 are present in the same transcription unit (120); miR-1 is the most abundant miR and is highly conserved in human myocardial cells (121). Mature miR-1-1 and miR-1-2 have the same gene sequence; the miR-13 family includes miR-133a-1, miR-133a-2 and miR-133b $(122,123)$. During heart development, the deletion or mutation of the essential gene Hand2 of muscle precursor cells in early embryonic development may lead to cardiac hypoplasia and even cardiac arrest (124). Mukai et al (125) revealed that miR-486-3p, miR-155-5p and miR-486-5p were increased in patients with cyanotic heart disease compared with those without heart disease. Furthermore, let-7e-5p and miR-1260a were decreased in patients with early-stage acyanotic heart disease compared with those without heart disease, suggesting that these miRs may be used for early diagnosis.

Zhao et al (126) reported that the expression of miR-1-2 was upregulated in myocardial and skeletal muscle cells. Overexpression of miR-1 during cardiac development may inhibit ventricular myocyte dilatation. It was also demonstrated that miR-1-2 targets the Hand2 gene, which may block Hand2 protein synthesis and regulate cardiac morphogenesis (127); its abnormal expression may even lead to CHD (127). Another study reported that the mouse phenotypes were almost normal with deletion of either miR-133a-1 or miR-133a-2, but the synchronous lack of these two miRs led to a fatal ventricular septal defect in approximately half of the mice during the embryonic period (128). Thus, miR-133 can promote myoblast proliferation, and miR-1 can stimulate myogenic differentiation. Therefore, miR-1 and miR-133 exhibit a dialectical association, and abnormalities may lead to the development of CHD.

Chen and $\mathrm{Li}$ (129) quantified the levels of miR-19a by RT-qPCR in the plasma of 30 patients with CHD, and changes in the levels of miR-19a, miR-130a and miR-27b were also confirmed using RT-qPCR. The levels of miR-19a, miR-198, miR-130a and miR-27b were significantly increased in patients suffering from pulmonary arterial hypertension induced by CHD. These observations suggest that circulating miR-19a may be a novel biomarker for the diagnosis of pulmonary arterial hypertension induced by CHD.

The abovementioned data summarize the differences in expression of miRs in patients with HF (including cardiomyopathy, hypertension, D-HF and CHD). Their clinical significance as HF biomarkers were analyzed (Table II).

Limitations of miRs as biomarkers of HF. Establishing an accurate, reliable circulating miR system for HF diagnosis, prognosis and prediction of response to treatment is challenging, from sample collection and processing to data analysis. First, overlapping between various failure mechanisms leads to difficulties in assessing which mechanisms underlie the expression changes in circulating miRs. Second, serum or plasma are the first choices for sample selection and handling, but the level of circulating biomarker miRs was low, which to some degree impedes the detection of miRs (130). Serum hemolysis may result in waste of samples (131). Furthermore, the serum level of miRs was higher than for circulating plasma, indicating that serum samples can prevent potential interference caused by platelets and leukocytes during sample preparation (132). Therefore, use of the same type of material and synchronous sampling is important for the patient and control groups, as well as a standard scheme to avoid sample hemolysis, minimizing differences between patient selection and classification. Third, some studies have reported fluctuation of miR levels in patients with $\mathrm{HF}$ following treatment $(133,134)$. Blood samples were collected at three stages, namely prior to, during and following treatment. A fourth factor was the choice of measurement platform for miR. As indicated in Fig. 2, all research techniques have advantages and disadvantages, but the most commonly used method is RT-qPCR. This method is more sensitive and more cost-effective compared with other methods, but its primary limitation is the inability to detect new miRs. In addition, the standardization of miR expression level may be difficult, as the expression levels of miRs fluctuate with changes in physiological and pathological conditions. Therefore, standard methods are commonly used for the experiments, including the use of equal amounts of starting material (such as serum or plasma), which is more reliable for endogenous miRs for data normalization.

As observed in the present study, the clinical manifestations of HF caused by expression changes of different miRs are similar, and the changes in miR expression caused by 


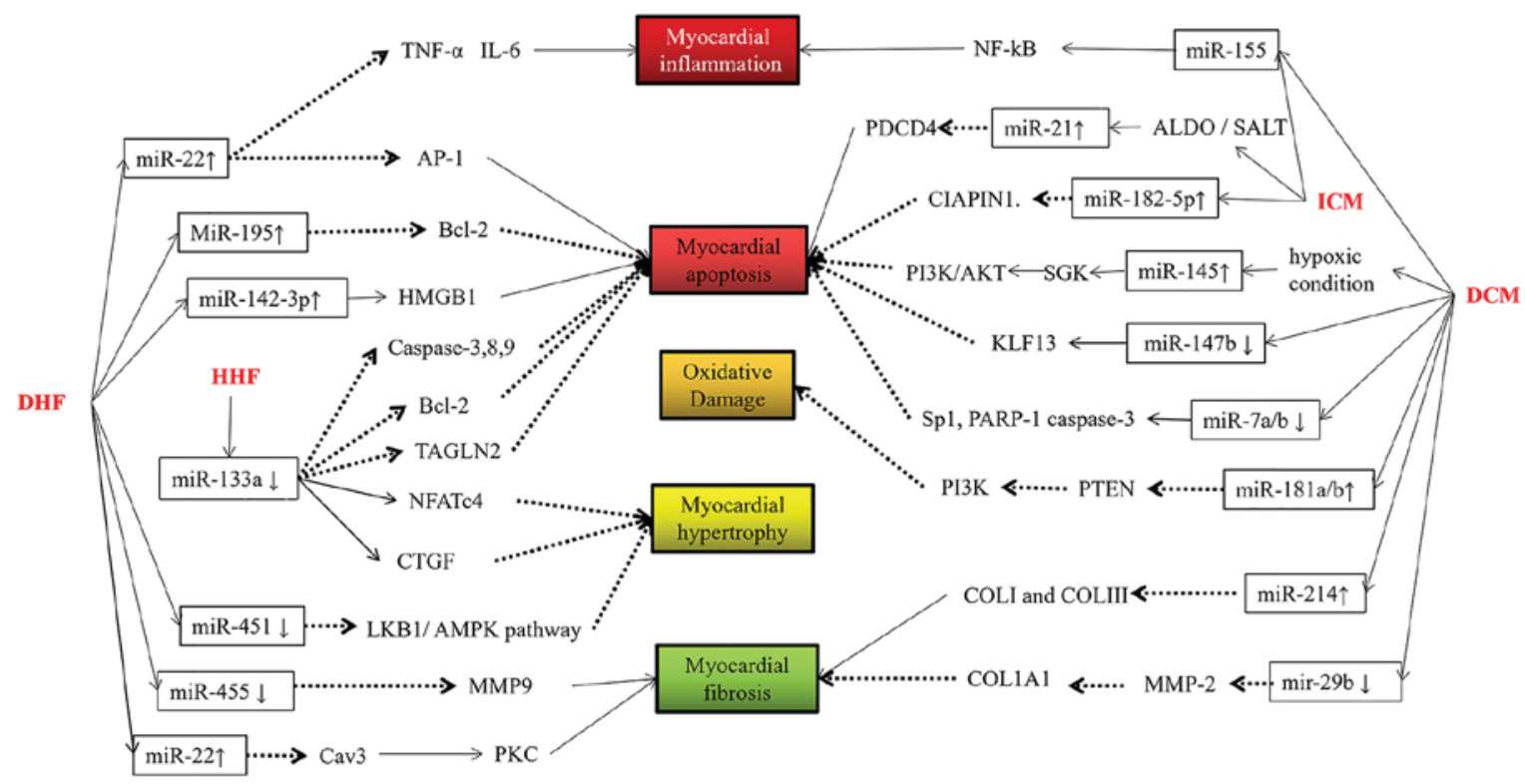

Figure 3. MiRNAs in different heart failure have different regulatory mechanisms for pathogenesis of heart failure. Solid lines represent positive regulation and dashed lines represent negative regulation. The nock of the arrow controls the tip of the arrow, for example, upregulation of miR-22 in diabetic heart failure alleviated myocardial inflammation through inhibiting tumor necrosis factor- $\alpha$ or interleukin- 6 expression. TNF- $\alpha$, tumor necrosis factor- $\alpha$; IL- 6 , interleukin-6; AP-1, activator protein-1; HMGB1, high-mobility group box 1 protein; Bcl-2, B-cell lymphoma-2; TAGLN2, Transgelin 2; NFATC4, Nuclear Factor Of Activated T Cells; LKB1, Liver kinase B1; AMPK, adenosine monophosphate-activated protein kinase; MMP-9, matrix metalloproteinase-9; CAV3, Caveolin 3; PKC, protein kinase C; PDCD4, programmed cell death 4; ALDO, aldosterone; CIAPIN1, cytokine-induced anti-apoptotic molecule; KLF13, Kruppel-like transcription factor 13; SGK, Serum and Glucocorticoid Induced Kinase; SP1, specific protein 1; PI3K, phosphatidylinositol-4,5-bisphosphate 3-kinase; PTEN, phosphatase and tensin homolog deleted on chromosome 10; MMP-2, matrix metalloproteinase-2; Colla1, collagen 1A1; Col III, type III collagen; Col I, type I collagen; PARP 1, poly ADP-ribose polymerase 1.

different types of HF may also be similar, reflecting the complexity of miR biology.

\section{Conclusion}

As described in Fig. 3, the expression of miR-145 was upregulated and the expression of miR-147 and miR-7 was downregulated in DCM, ultimately inhibiting cardiomyocyte apoptosis. The upregulation of miR-181 inhibited oxidative stress. Furthermore, upregulation of miR-214 and downregulation of miR-29b attenuated cardiomyocyte fibrosis, which may be a late regulatory mechanism. By contrast, upregulation of miR-155 promotes cardiomyocyte inflammation, which may be an early regulatory mechanism. The abovementioned miRs appear to be promising potential candidate markers associated with DCM.

In ischemic HF, upregulation of miR-155 intensified cardiomyocyte inflammation, and upregulation of miR-182 promoted apoptosis, which may be an early indicator of this condition. Upregulation of miR-21 alleviated apoptosis via negative feedback regulation. Thus, miR-21 may be a late-age indicator in ischemic HF.

In hypertensive HF, downregulation of miR-133 inhibited cardiomyocyte hypertrophy and promoted cardiomyocyte apoptosis, which may be a late-stage decompensation.

In D-HF, upregulation of miR-22 reduced cardiomyocyte fibrosis, apoptosis and inflammation, and downregulation of miR-455 restrained cell fibrosis, which may be a late indicator of diabetic heart failure, whereas the upregulation of
miR-195 and miR-142 aggravated apoptosis and miR-451 downregulation exacerbated cardiomyocyte hypertrophy, which may be an early indicator.

In conclusion, miR-155, miR-22 and miR-133 appear to be promising markers of the development, diagnosis and prognosis of HF. However, further research is required to determine whether there is an efficient miR template for application in clinical oncology practice.

\section{Acknowledgements}

Not applicable.

\section{Funding}

The present study was supported by the National Natural Science Foundation of China (grant no. 81372150 to BHL and grant nos. nos. 91739301 and 91849102 to MH).

\section{Availability of data and materials}

Not applicable.

\section{Authors' contributions}

MH and BHL designed and conceived the study. YMH, WWL and JW provided advice and assistance. YMH wrote the manuscript. All the authors have contributed to and approved the final version of the manuscript. 


\section{Ethics approval and consent to participate}

Not applicable.

\section{Patient consent for publication}

Not applicable.

\section{Competing interests}

The authors declare that they have no competing interests.

\section{References}

1. Cordes KR and Srivastava D: MicroRNA regulation of cardiovascular development. Circ Res 104: 724-732, 2009.

2. Anderson ME, Brown JH and Bers DM: CaMKII in myocardial hypertrophy and heart failure. J Mol Cell Cardiol 51: 468-473, 2011

3. Yang J, Savvatis K, Kang JS, Fan P, Zhong H, Schwartz K, Barry V, Mikels-Vigdal A, Karpinski S, Kornyeyev D, et al: Targeting LOXL2 for cardiac interstitial fibrosis and heart failure treatment. Nat Commun 7: 13710, 2016.

4. Kawakami H, Kubota Y, Takeno S, Miyazaki Y, Wada T, Hamada R and Nanashima A: Gastrointestinal: Severe congestive heart failure and acute gastric mucosal necrosis. J Gastroenterol Hepatol 32: 949, 2017.

5. Petrovic D: Cytopathological basis of heart failure-cardiomyocyte apoptosis, interstitial fibrosis and inflammatory cell response. Folia Biol (Praha) 50: 58-62, 2004.

6. Orsborne C, Chaggar PS, Shaw SM and Williams SG: The renin-angiotensin-aldosterone system in heart failure for the non-specialist: The past, the present and the future. Postgrad Med J 93: 29-37, 2017

7. Polyakova V, Loeffler I, Hein S, Miyagawa S, Piotrowska I, Dammer S, Risteli J, Schaper J and Kostin S: Fibrosis in endstage human heart failure: Severe changes in collagen metabolism and MMP/TIMP profiles. Int J Cardiol 151: 18-33, 2011.

8. Romaine SP, Tomaszewski M, Condorelli G and Samani NJ: MicroRNAs in cardiovascular disease: An introduction for clinicians. Heart 101: 921-928, 2015.

9. Liu X, Tong Z, Chen K, Hu X, Jin H and Hou M: The role of miRNA-132 against apoptosis and oxidative stress in heart failure. Biomed Res Int 2018: 3452748, 2018.

10. Gómez AM, Valdivia HH, Cheng H, Lederer MR, Santanaet LF, Cannel MB, McCune SA, Altschuld RA and Lederer WJ: Defective excitation-contraction coupling in experimental cardiac hypertrophy and heart failure. Science 276: 800-806, 1997.

11. Kumar R, Woo MA, Birrer BV, Macey PM, Fonarow GC, Hamilton MA and Harper RM: Mammillary bodies and fornix fibers are injured in heart failure. Neurobiol Dis 33: $236-242,2009$

12. Neupane B, Zhou Q, Gawaz M and Gramlich M: Personalized medicine in inflammatory cardiomyopathy. Per Med 15: 127-136, 2018.

13. Dludla PV, Dias SC, Obonye N, Johnson R, Louw J and Nkambule BB: A systematic review on the protective effect of $\mathrm{N}$-acetyl cysteine against diabetes-associated cardiovascular complications. Am J Cardiovasc Drugs 18: 283-298, 2018.

14. Güven Bağla A, Içkin Gülen M, Ercan F, Aşgün F, Ercan E and Bakar C: Changes in kidney tissue and effects of erythropoietin after acute heart failure. Biotech Histochem 93: 340-353, 2018

15. Lindner K, Haier J, Wang Z, Watson DI, Hussey DJ and Hummel R: Circulating microRNAs: Emerging biomarkers for diagnosis and prognosis in patients with gastrointestinal cancers. Clin Sci (Lond) 128: 1-15, 2015.

16. Li R, Geng HH, Xiao J, Qin XT, Wang F, Xing JH, Xia YF, Mao Y, Liang JW and Jia XP: miR-7a/b attenuates post-myocardial infarction remodeling and protects $\mathrm{H} 9 \mathrm{c} 2$ cardiomyoblast against hypoxia-induced apoptosis involving Sp1 and PARP-1. Sci Rep 6: 29082, 2016.
17. Ball JP, Syed M, Marañon RO, Hall ME, Kc R, Reckelhoff JF, Yanes Cardozo LL and Romero DG: Role and regulation of MicroRNAs in aldosterone-mediated cardiac injury and dysfunction in male rats. Endocrinology 158: 1859-1874, 2017.

18. Deng W, Wang Y, Long X, Zhao R, Wang Z, Liu Z, Cao S and Shi B: miR-21 reduces hydrogen peroxide-induced apoptosis in c-kit+ cardiac stem cells in vitro through PTEN/PI3K/Akt signaling. Oxid Med Cell Longev 2016: 5389181, 2016.

19. Cheng M, Wu G, Song Y, Wang L, Tu L, Zhang L and Zhang C: Celastrol-induced suppression of the MiR-21/ERK signalling pathway attenuates cardiac fibrosis and dysfunction. Cell Physiol Biochem 38: 1928-1938, 2016.

20. Xiao J, Pan Y, Li XH, Yang XY, Feng YL, Tan HH, Jiang L, Feng $\mathrm{J}$ and $\mathrm{Yu} X Y$ : Cardiac progenitor cell-derived exosomes prevent cardiomyocytes apoptosis through exosomal miR-21 by targeting PDCD4. Cell Death Dis 7: e2277, 2016.

21. Tao H, Chen ZW, Yang JJ and Shi KH: MicroRNA-29a suppresses cardiac fibroblasts proliferation via targeting VEGF-A/MAPK signal pathway. Int J Biol Macromol 88: 414-423, 2016.

22. Liu CZ, Zhong Q and Huang YQ: Elevated plasma miR-29a levels are associated with increased carotid intima-media thickness in atherosclerosis patients. Tohoku J Exp Med 241: 183-188, 2017.

23. Lu Z, Wang F, Yu P, Wang X, Wang Y, Tang ST and Zhu HQ: Inhibition of miR-29b suppresses MAPK signaling pathway through targeting SPRY1 in atherosclerosis. Vascul Pharmacol 102: 29-36, 2018.

24. Sassi Y, Avramopoulos P, Ramanujam D, Grüter L, Werfel S, Giosele S, Brunner A, Esfandyari D, Papadopoulou AS, De Strooper B, et al: Cardiac myocyte miR-29 promotes pathological remodeling of the heart by activating Wnt signaling. Nat Commun 8: 1614, 2017.

25. Panizo S, Carrillo-López N, Naves-Díaz M, Solache-Berrocal G, Martínez-Arias L, Rodrigues-Díez RR, Fernández-Vázquez A, Martínez-Salgado C, Ruiz-Ortega M, Dusso A, et al: Regulation of miR-29b and miR-30c by vitamin D receptor activators contributes to attenuate uraemia-induced cardiac fibrosis. Nephrol Dial Transplant 32: 1831-1840, 2017.

26. Heid J, Cencioni C, Ripa R, Baumgart M, Atlante S, Milano G, Scopece A, Kuenne C, Guenther S, Azzimato V, et al: Age-dependent increase of oxidative stress regulates microRNA-29 family preserving cardiac health. Sci Rep 7: 16839, 2017.

27. Chen L, Ji Q, Zhu H, Ren Y, Fan Z and Tian N: miR-30a attenuates cardiac fibrosis in rats with myocardial infarction by inhibiting CTGF. Exp Ther Med 15: 4318-4324, 2018.

28. Roca-Alonso L, Castellano L, Mills A, Dabrowska AF, Sikkel MB, Pellegrino L, Jacob J, Frampton AE, Krell J, Coombes RC, et al: Myocardial MiR-30 downregulation triggered by doxorubicin drives alterations in $\beta$-adrenergic signaling and enhances apoptosis. Cell Death Dis 6: e1754, 2015.

29. Lai L, Chen J, Wang N, Zhu G, Duan X and Ling F: MiRNA-30e mediated cardioprotection of ACE2 in rats with Doxorubicin-induced heart failure through inhibiting cardiomyocytes autophagy. Life Sci 169: 69-75, 2017.

30. van Middendorp LB, Kuiper M, Munts C, Wouters P, Maessen JG, van Nieuwenhoven FA and Prinzen FW: Local microRNA-133a downregulation is associated with hypertrophy in the dyssynchronous heart. ESC Heart Fail 4: 241-251, 2017.

31. Li Q, Lin X, Yang X and Chang J: NFATc4 is negatively regulated in miR-133a-mediated cardiomyocyte hypertrophic repression. Am J Physiol Heart Circ Physiol 298: H1340-H1347, 2010.

32. Li AY, Yang Q and Yang K: miR-133a mediates the hypoxia-induced apoptosis by inhibiting TAGLN2 expression in cardiac myocytes. Mol Cell Biochem 400: 173-181, 2015.

33. Rangrez AY, Hoppe P, Kuhn C, Zille E, Frank J, Frey N and Frank D: MicroRNA miR-301a is a novel cardiac regulator of Cofilin-2. PLoS One 12: e0183901, 2017.

34. Dong H, Dong S, Zhang L, Gao X, Lv G, Chen W and Shao S: MicroRNA-214 exerts a Cardio-protective effect by inhibition of fibrosis. Anat Rec (Hoboken) 299: 1348-1357, 2016.

35. Chaturvedi P, Kalani A, Medina I, Familtseva A and Tyagi SC: Cardiosome mediated regulation of MMP9 in diabetic heart: Role of mir29b and mir455 in exercise. J Cell Mol Med 19: 2153-2161, 2015.

36. Liu N, Shi YF, Diao HY, Li YX, Cui Y, Song XJ, Tian X, Li TY and Liu B: MicroRNA-135a regulates apoptosis induced by hydrogen peroxide in rat cardiomyoblast cells. Int J Biol Sci 13: $13-21,2017$ 
37. Wang Y, Ouyang M, Wang Q and Jian Z: MicroRNA-142-3p inhibits hypoxia/reoxygenation-induced apoptosis and fibrosis of cardiomyocytes by targeting high mobility group box 1 . Int J Mol Med 38: 1377-1386, 2016.

38. Yang F, Li T, Dong Z and Mi R: MicroRNA-410 is involved in mitophagy after cardiac ischemia/reperfusion injury by targeting high-mobility group box 1 protein. J Cell Biochem 119: 2427-2439, 2018.

39. Zhang S, Zhang R, Wu F and LI X: MicroRNA-208a regulates $\mathrm{H} 9 \mathrm{c} 2$ cells simulated ischemia-reperfusion myocardial injury via targeting CHD9 through Notch/NF-kappa B signal pathways. Int Heart J 59: 580-588, 2018.

40. Fan ZG, Qu XL, Chu P, Gao YL, Gao XF, Chen SL and Tian NL: MicroRNA-210 promotes angiogenesis in acute myocardial infarction. Mol Med Rep 17: 5658-5665, 2018

41. Zhang Y, Fang $\mathbf{J}$ and Ma H: Inhibition of miR-182-5p protects cardiomyocytes from hypoxia-induced apoptosis by targeting CIAPIN1. Biochem Cell Biol 96: 646-654, 2018.

42. Liu X, Tong Z, Chen K, Hu X, Jin H and Hou M: The role of miRNA-132 against apoptosis and oxidative stress in heart failure. Biomed Res Int 2018: 3452748, 2018.

43. Zhou G, Li C, Feng J, Zhang J and Fang Y: lncRNA UCA1 is a novel regulator in cardiomyocyte hypertrophy through targeting the miR-184/HOXA9 axis. Cardiorenal Med 8: 130-139, 2018.

44. Rubiś P, Totoń-Żurańska J, Wiśniowska-Śmiałek S, Holcman K, Kołton-Wróż M, Wołkow P, Wypasek E, Natorska J, Rudnicka-Sosin L, Pawlak A, et al: Relations between circulating microRNAs (miR-21, miR-26, miR-29, miR-30 and miR-133a), extracellular matrix fibrosis and serum markers of fibrosis in dilated cardiomyopathy. Int J Cardiol 231: 201-206, 2017.

45. Ji Y, Qiu M, Shen Y, Gao L, Wang Y, Sun W, Li X, Lu Y and Kong X: MicroRNA-327 regulates cardiac hypertrophy and fibrosis induced by pressure overload. Int J Mol Med 41: 1909-1916, 2018

46. Lu Y and Wu F: A new miRNA regulator, miR-672, reduces cardiac hypertrophy by inhibiting JUN expression. Gene 648: 21-30, 2018.

47. Wang Y, Cai H, Li H, Gao Z and Song K: Atrial overexpression of microRNA-27b attenuates angiotensin II-induced atrial fibrosis and fibrillation by targeting ALK5. Hum Cell 31: 251-260, 2018

48. Yang J, Chen L, Ding J, Zhang J, Fan Z, Yang C, Yu Q and Yang J: Cardioprotective effect of miRNA-22 on hypoxia/reoxygenation induced cardiomyocyte injury in neonatal rats. Gene 579: 17-22, 2016.

49. Zhang L, Yin H, Jiao L, Liu T, Gao Y, Shao Y, Zhang Y, Shan H, Zhang Y and Yang B: Abnormal downregulation of caveolin-3 mediates the pro-fibrotic action of MicroRNA-22 in a model of myocardial infarction. Cell Physiol Biochem 45: 1641-1653, 2018 .

50. Zheng L, Lin S and Lv C: MiR-26a-5p regulates cardiac fibroblasts collagen expression by targeting ULK1. Sci Rep 8: 2104, 2018.

51. Gu M, Wang J, Wang Y, Xu Y, Zhang Y, Wu W and Liao S: MiR-147b inhibits cell viability and promotes apoptosis of rat H9c2 cardiomyocytes via down-regulating KLF13 expression. Acta Biochim Biophys Sin (Shanghai) 50: 288-297, 2018.

52. Sun N, Meng F, Xue N, Pang G, Wang Q and Ma H: Inducible miR-145 expression by HIF-1a protects cardiomyocytes against apoptosis via regulating SGK1 in simulated myocardial infarction hypoxic microenvironment. Cardiol J 25: 268-278, 2018.

53. Chen Z, Zhang S, Guo C, Li J and Sang W: Downregulation of miR-200c protects cardiomyocytes from hypoxia-induced apoptosis by targeting GATA-4. Int J Mol Med 39: 1589-1596, 2017.

54. Meng X, Ji Y, Wan Z, Zhao B, Feng C, Zhao J, Li H and Song Y: Inhibition of miR-363 protects cardiomyocytes against hypoxia-induced apoptosis through regulation of Notch signaling. Biomed Pharmacother 90: 509-516, 2017.

55. Li T, Yang GM, Zhu Y, Wu Y, Chen XY, Lan D, Tian K and Liu LM: Diabetes and hyperlipidemia induce dysfunction of VSMCs: Contribution of the metabolic inflammation/miRNA pathway. Am J Physiol Endocrinol Metab 308: E257-E269, 2015.

56. Gallego I, Beaumont J, López B, Ravassa S, Gómez-Doblas JJ, Moreno MU, Valencia F, de Teresa E, Díez J and González A: Potential role of microRNA-10b down-regulation in cardiomyocyte apoptosis in aortic stenosis patients. Clin Sci (Lond) 130: 2139-2149, 2016
57. Hang P, Sun C, Guo J, Zhao J and Du Z: BDNF-mediates down-regulation of MicroRNA-195 inhibits ischemic cardiac apoptosis in rats. Int J Biol Sci 12: 979-989, 2016.

58. Blumensatt M, Fahlbusch P, Hilgers R, Bekaert M, Herzfeld de Wiza D, Akhyari P, Ruige JB and Ouwens DM: Secretory products from epicardial adipose tissue from patients with type 2 diabetes impair mitochondrial $\beta$-oxidation in cardiomyocytes via activation of the cardiac renin-angiotensin system and induction of miR-208a. Basic Res Cardiol 112: 2, 2017.

59. Marchand A, Atassi F, Mougenot N, Clergue M, Codoni V, Berthuin J, Proust C, Trégouët DA, Hulot JS and Lompré AM: miR-322 regulates insulin signaling pathway and protects against metabolic syndrome-induced cardiac dysfunction in mice. Biochim Biophys Acta 1862: 611-621, 2016.

60. Zhong C, Wang K, Liu Y, Lv D, Zheng B, Zhou Q, Sun Q, Chen P, Ding S, Xu Y and Huang H: miR-19b controls cardiac fibroblast proliferation and migration. J Cell Mol Med 20: 1191-1197, 2016.

61. Pan L, Huang BJ, Ma XE, Wang SY, Feng J, Lv F, Liu Y, Liu Y, Li CM, Liang DD, et al: MiR-25 protects cardiomyocytes against oxidative damage by targeting the mitochondrial calcium uniporter. Int J Mol Sci 16: 5420-5433, 2015.

62. Das S, Kohr M, Dunkerly-Eyring B, Lee DI, Bedja D, Kent OA, Leung AK, Henao-Mejia J, Flavell RA and Steenbergen C: Divergent effects of miR-181 family members on myocardial function through protective cytosolic and detrimental mitochondrial microRNA targets. J Am Heart Assoc 6: pii: e004694, 2017.

63. Palomer X, Capdevila-Busquets E, Botteri G, Davidson MM, Rodríguez C, Martínez-González J, Vidal F, Barroso E, Chan TO, Feldman AM, et al: miR-146a targets Fos expression in human cardiac cells. Dis Model Mech 8: 1081-1091, 2015.

64. Khamaneh AM, Alipour MR, Sheikhzadeh Hesari F and Ghadiri Soufi F: A signature of microRNA-155 in the pathogenesis of diabetic complications. J Physiol Biochem 71: 301-309, 2015

65. Fang Y, Chen H, Hu Y, Li Q, Hu Z, Ma T and Mao X: Burkholderia pseudomallei-derived miR-3473 enhances $\mathrm{NF}-\mathrm{\kappa B}$ via targeting TRAF3 and is associated with different inflammatory responses compared to Burkholderia thailandensis in murine macrophages. BMC Microbiol 16: 283, 2016.

66. Kuwabara Y, Horie T, Baba O, Watanabe S, Nishiga M, Usami S, Izuhara M, Nakao T, Nishino T, Otsu K, et al: MicroRNA-451 exacerbates lipotoxicity in cardiac myocytes and high-fat diet-induced cardiac hypertrophy in mice through suppression of the LKB1/AMPK Pathway. Circ Res 116: 279-288, 2015.

67. Cohen-Solal A, Beauvais F and Logeart D: Heart failure and diabetes mellitus: Epidemiology and management of an alarming association. J Card Fail 14: 615-625, 2008.

68. Nargesi AA, Esteghamati S, Heidari B, Hafezi-Nejad N, Sheikhbahaei S, Pajouhi A, Nakhjavani M and Esteghamati A: Nonlinear relation between pulse pressure and coronary heart disease in patients with type 2 diabetes or hypertension. J Hypertens 34: 974-980, 2016.

69. Puntmann VO, Carr-White G, Jabbour A, Yu CY, Gebker R, Kelle S, Hinojar R, Doltra A, Varma N, Child N, et al: T1-mapping and outcome in nonischemic cardiomyopathy: All-cause mortality and heart failure. JACC Cardiovasc Imaging 9: 40-50, 2016.

70. Cahill TJ, Ashrafian H and Watkins H: Genetic cardiomyopathies causing heart failure. Circ Res 113: 660-675, 2013.

71. Ortega A, Roselló-Lletí E, Tarazón E, Molina-Navarro MM, Martínez-Dolz L, González-Juanatey JR, Lago F, Montoro-Mateos JD, Salvador A, Rivera M and Portolés M: Endoplasmic reticulum stress induces different molecular structural alterations in human dilated and ischemic cardiomyopathy. PLoS One 9: e107635, 2014

72. Yeung F, Chung E, Guess MG, Bell ML and Leinwand LA Myh7b/miR-499 gene expression is transcriptionally regulated by MRFs and Eos. Nucleic Acids Res 40: 7303-7318, 2012.

73. Abraityte A, Lunde IG, Askevold ET, Michelsen AE, Christensen G, Aukrust P, Yndestad A, Fiane A, Andreassen A, Aakhus S, et al: Wnt5a is associated with rightventricular dysfunction and adverse outcome in dilated cardiomyopathy. Sci Rep 7: 3490, 2017

74. Yamamoto S, Yang G, Zablocki D, Liu J, Hong C, Kim SJ, Soler S, Odashima M, Thaisz J, Yehia G, et al: Activation of Mst1 causes dilated cardiomyopathy by stimulating apoptosis without compensatory ventricular myocyte hypertrophy. J Clin Invest 111: 1463-1474, 2003 
75. Zhang Y, Kanter EM and Yamada KA: Remodeling of cardiac fibroblasts following myocardial infarction results in increased gap junction intercellular communication. Cardiovasc Pathol 19: e233-e240, 2010.

76. Naga Prasad SV, Gupta MK, Duan ZH, Surampudi VS, Liu CG, Kotwal A, Moravec CS, Starling RC, Perez DM, Sen S, et al: A unique microRNA profile in end-stage heart failure indicates alterations in specific cardiovascular signaling networks. PLoS One 12: e0170456, 2017.

77. Enes Coşkun M, Kervancioğlu M, Öztuzcu S, Yılmaz Coşkun F, Ergün S, Başpınar O, Kılınç M, Temel L and Coşkun MY: Plasma microRNA profiling of children with idiopathic dilated cardiomyopathy. Biomarkers 21: 56-61, 2016.

78. Miyamoto SD, Karimpour-Fard A, Peterson V, Auerbach SR, Stenmark KR, Stauffer BL and Sucharov CC: Circulating microRNA as a biomarker for recovery in pediatric dilated cardiomyopathy. J Heart Lung Transplant 34: 724-733, 2015.

79. Leger KJ, Singh S, Canseco D, VonGrote EC, Karim-Ud-Din S, Collins SC Thibodeau JT, Mishkin JD, Patel PC, Markham DW, et al: Abstract 13120: Identification of novel circulating microRNAs in ischemic cardiomyopathy utilizing whole blood microRNA profiling. Circulation 128 (Suppl 22): A13120, 2013

80. Zeng $\mathrm{X}$, Li $\mathrm{X}$ and Wen $\mathrm{H}$ : Expression of circulating microRNA-182, CITED2 and HIF-1 in ischemic cardiomyopathy and their correlation. J Clin Cardiol 33: 119-122, 2017 (In Chinese).

81. Olson E and Rooij EV: Dual targeting of miR-208 and miR-499 in the treatment of cardiac disorders. US Patent 14104886. Filed December 12, 2013; issued June 26, 2014.

82. Fichtlscherer S, De Rosa S, Fox H, Schwietz T, Fischer A, Liebetrau C, Weber M, Hamm CW, Röxe T, Müller-Ardogan M, et al: Circulating microRNAs in patients with coronary artery disease. Circ Res 107: 677-684, 2010.

83. Li X, Liu CY, Li YS, Xu J, Li DG, Li X and Han D: Deep RNA sequencing elucidates microRNA-regulated molecular pathways in ischemic cardiomyopathy and nonischemic cardiomyopathy. Genet Mol Res 15: gmr7465, 2016.

84. Phelan D, Watson C, Martos R, Collier P, Patle A, Donnelly S, Ledwidge M, Baugh $\mathrm{J}$ and McDonald $\mathrm{K}$ : Modest elevation in BNP in asymptomatic hypertensive patients reflects sub-clinical cardiac remodeling, inflammation and extracellular matrix changes. PLoS One 7: e49259, 2012.

85. Mohammed SF, Hussain S, Mirzoyev SA, Edwards WD, Maleszewski JJ and Redfield MM: Coronary microvascular rarefaction and myocardial fibrosis in heart failure with preserved ejection fraction. Circulation 131: 550-559, 2015

86. Shyu KG, Wang BW, Cheng WP and Lo HM: MicroRNA-208a increases myocardial endoglin expression and myocardial fibrosis in acute myocardial infarction. Can J Cardiol 31 679-690, 2015.

87. Cengiz M, Karatas OF, Koparir E, Yavuzer S, Ali C, Yavuzer H Kirat E, Karter Y and Ozen M: Differential expression of hypertension-associated microRNAs in the plasma of patients with white coat hypertension. Medicine (Baltimore) 94: e693, 2015.

88.Fu M, Gao Y, Zhou Q, Zhang Q, Peng Y, Tian K, Wang J and Zheng $\mathrm{X}$ : Human cytomegalovirus latent infection alters the expression of cellular and viral microRNA. Gene 536: 272-278, 2014.

89. Stern-Ginossar N, Saleh N, Goldberg MD, Prichard M, Wolf DG and Mandelboim O: Analysis of human cytomegalovirus-encoded microRNA activity during infection. J Virol 83 10684-10693, 2009.

90.Li S, Zhu J, Zhang W, Chen Y, Zhang K, Popescu LM, Ma X, Lau WB, Rong R, Yu X, et al: Signature microRNA expression profile of essential hypertension and its novel link to human cytomegalovirus infection. Circulation 124: 175-184, 2011.

91. Ding M, Wang X, Wang C, Liu X, Zen K, Wang W, Zhang CY and Zhang C: Distinct expression profile of HCMV encoded miRNAs in plasma from oral lichen planus patients. J Transl Med 15: 133, 2017.

92.Kellawan JM, Johansson RE, Harrell JW, Sebranek JJ, Walker BJ, Eldridge MW and Schrage WG: Exercise vasodilation is greater in women: Contributions of nitric oxide synthase and cyclooxygenase. Eur J Appl Physiol 115: 1735-1746, 2015.

93. Dolcino M, Puccetti A, Barbieri A, Bason C, Tinazzi E, Ottria A, Patuzzo G, Martinelli N and Lunardi C: Infections and autoimmunity: Role of human cytomegalovirus in autoimmune endothelial cell damage. Lupus 24: 419-432, 2015.
94. Kontaraki JE, Marketou ME, Zacharis EA, Parthenakis FI and Vardas PE: MiR-1, miR-9 and miR-126 levels in peripheral blood mononuclear cells of patients with essential hypertension associate with prognostic indices of ambulatory blood pressure monitoring. Eur Heart J 34 (Suppl 1): S5158, 2013.

95. Kontaraki JE, Marketou ME, Zacharis EA, Parthenakis FI and Vardas PE: Mir-143/mir-145 levels in peripheral blood mononuclear cells associate with ambulatory blood pressure monitoring parameters in patients with essential hypertension. Eur Heart J 34 (Suppl 1): S5656, 2013.

96. Dickinson BA, Semus HM, Montgomery RL, Stack C, Latimer PA, Lewton SM, Lynch JM, Hullinger TG, Seto AG and van Rooij E: Plasma microRNAs serve as biomarkers of therapeutic efficacy and disease progression in hypertension-induced heart failure. Eur J Heart Fail 15: 650-659, 2013.

97. Hou YL, LI SL and Liu LL: Effects of MicroRNA-137 and AngII on cardiac remodeling in spontaneously hypertensive rats. Chin J Comp Med 7, 2016 (In Chinese)

98. Li JZ, Tang XN,LiTT, Liu LJ, Yu SY,Zhou GY, Shao QR, Sun HP, Wu C and Yang Y: Paeoniflorin inhibits doxorubicin-induced cardiomyocyte apoptosis by downregulating microRNA-1 expression. Exp Ther Med 11: 2407-2412, 2016.

99. Yang Q, Jia C, Wang P, Xiong M, Cui J, Li L, Wang W, Wu Q, Chen Y and Zhang T: MicroRNA-505 identified from patients with essential hypertension impairs endothelial cell migration and tube formation. Int J Cardiol 177: 925-934, 2014

100. Li Y, Wu H, Zhu M, Shelat H, Qu J, Zheng M, Yuan J, Yuan G, $\mathrm{Xu}$ J, Wang $\mathrm{H}$ and Geng YJ: Insulin-like growth factor prevents diabetes induced cardiomyopathy mediated by MICRORNA-1. J Am College Cardiol 55: A21.E196, 2010.

101. Finn NA, Eapen D, Manocha P, Al Kassem H, Lassegue B, Ghasemzadeh N, Quyyumi A and Searles CD: Coronary heart disease alters intercellular communication by modifying microparticle-mediated microRNA transport. FEBS Lett 587: 3456-3463, 2013.

102. Dickstein K: Is substantial renal dysfunction in patients with heart failure no longer a contraindication for RAS inhibition? The power of a large, high-quality registry to illuminate major clinical issues. Eur Heart J 36: 2279-2280, 2015.

103. Shang F, Wang SC, Hsu CY, Miao Y, Martin M, Yin Y, Wu CC, Wang YT, Wu G, Chien S, et al: MicroRNA-92a mediates endothelial dysfunction in CKD. J Am Soc Nephrol 28: 3251-3261, 2017.

104. Valadi H, Ekström K, Bossios A, Sjöstrand M, Lee JJ and Lötvall JO: Exosome-mediated transfer of mRNAs and microRNAs is a novel mechanism of genetic exchange between cells. Nat Cell Biol 9: 654-659, 2007.

105. Wang C, Fan F, Cao Q, Shen C, Zhu H, Wang P, Zhao X, Sun X, Dong Z, Ma X, et al: Mitochondrial aldehyde dehydrogenase 2 deficiency aggravates energy metabolism disturbance and diastolic dysfunction in diabetic mice. J Mol Med (Berl) 94: 1229-1240, 2016

106. Wong AK, AlZadjali MA, Choy AM and Lang CC: Insulin resistance: A potential new target for therapy in patients with heart failure. Cardiovasc Ther 26: 203-213, 2008

107. Yu XY, Song YH, Geng YJ, Lin QX, Shan ZX, Lin SG and $\mathrm{Li}$ Y: Glucose induces apoptosis of cardiomyocytes via microRNA-1 and IGF-1. Biochem Biophys Res Commun 376: 548-552, 2008.

108. Horie T, Ono K, Nishi H, Iwanaga Y, Nagao K, Kinoshita M, Kuwabara Y, Takanabe R, Hasegawa K, Kita T and Kimura T: MicroRNA-133 regulates the expression of GLUT4 by targeting KLF15 and is involved in metabolic control in cardiac myocytes. Biochem Biophys Res Commun 389: 315-320, 2009.

109. Latronico MV, Catalucci D and Condorelli G: Emerging role of microRNAs in cardiovascular biology. Circ Res 101: 1225-1236, 2007

110. Greco S, Fasanaro P, Castelvecchio S, D'Alessandra Y, Arcelli D, Di Donato M, Malavazos A, Capogrossi MC, Menicanti L and Martelli F: MicroRNA dysregulation in diabetic ischemic heart failure patients. Diabetes 61: 1633-1641, 2012.

111. Nandi SS, Duryee MJ, Shahshahan HR, Thiele GM, Anderson DR and Mishra PK: Induction of autophagy markers is associated with attenuation of miR-133a in diabetic heart failure patients undergoing mechanical unloading. Am J Transl Res 7: 683-696, 2015.

112. Deng X, Liu Y, Luo M, Wu J, Ma R, Wan Q and Wu J: Circulating miRNA-24 and its target YKL-40 as potential biomarkers in patients with coronary heart disease and type 2 diabetes mellitus. Oncotarget 8: 63038-63046, 2017. 
113. Chavali V, Tyagi SC and Mishra PK: Differential expression of dicer, miRNAs, and inflammatory markers in diabetic Ins2+/Akita hearts. Cell Biochem Biophys 68: 25-35, 2014.

114. Izarra A, Moscoso I, Cañón S, Carreiro C, Fondevila D, Martín-Caballero J, Blanca V, Valiente I, Díez-Juan A and Bernad A: miRNA-1 and miRNA-133a are involved in early commitment of pluripotent stem cells and demonstrate antagonistic roles in the regulation of cardiac differentiation. J Tissue Eng Regen Med 11: 787-799, 2017.

115. Liu H, Yang L, Chen KH, Sun HY, Jin MW, Xiao GS, Wang Y and Li GR: SKF-96365 blocks human ether-à-go-go-related gene potassium channels stably expressed in HEK 293 cells. Pharmacol Res 104: 61-69, 2016.

116. van Solingen C, Bijkerk R, de Boer HC, Rabelink TJ and van Zonneveld AJ: The Role of microRNA-126 in vascular homeostasis. Curr Vasc Pharmacol 13: 341-351, 2015.

117. Fichtlscherer S, De Rosa S, Fox H, Schwietz T, Fischer A, Liebetrau C, Weber M, Hamm CW, Röxe T, Müller-Ardogan M, et al: Circulating microRNAs in patients with coronary artery disease. Circ Res 107: 677-684, 2010

118. Škrha P, Hajer J, Anděl M, Hořínek A and Korabečná M: miRNA as a new marker of diabetes mellitus and pancreatic carcinoma progression. Cas Lek Cesk 154: 122-126, 2015 (In Czech).

119. Talmud PJ: How to identify gene-environment interactions in a multifactorial disease: CHD as an example. Proc Nutr Soc 63: 5-10, 2004.

120. Carè A, Catalucci D, Felicetti F, Bonci D, Addario A, Gallo $\mathrm{P}$ Bang ML, Segnalini P, Gu Y, Dalton ND, et al: MicroRNA-133 controls cardiac hypertrophy. Nat Med 13: 613-618, 2007.

121. Wang L, Tian D, Hu J, Xing H, Sun M, Wang J, Jian Q and Yang H: MiRNA-145 regulates the development of congenital heart disease through targeting FXN. Pediatr Cardiol 37: 629-636, 2016.

122. Feng Y, Niu LL, Wei W, Zhang WY, Li XY, Cao JH and Zhao SH: A feedback circuit between miR-133 and the ERK1/2 pathway involving an exquisite mechanism for regulating myoblast proliferation and differentiation. Cell Death Dis 4: e934, 2013

123. Liu N, Bezprozvannaya S, Williams AH, Qi X, Richardson JA, Bassel-Duby $\mathrm{R}$ and Olson EN: microRNA-133a regulates cardiomyocyte proliferation and suppresses smooth muscle gene expression in the heart. Genes Dev 22: 3242-3254, 2008.

124. Shan ZX, Lin QX, Deng CY, Zhou ZL, Zhang XC, Fu YH and Yu XY: Plasmid-mediated miRNA-1-2 specifically inhibits Hand 2 protein expression in H9C2 cells. Nan Fang Yi Ke Da Xue Xue Bao 28: 1559-1561, 2008 (In Chinese).
125. Mukai N, Nakayama Y, Murakami S, Tanahashi T, Sessler DI, Ishii S, Ogawa $S$, Tokuhira $N$, Mizobe $T$, Sawa $T$ and Nakajima Y: Potential contribution of erythrocyte microRNA to secondary erythrocytosis and thrombocytopenia in congenital heart disease. Pediatr Res 83: 866-873, 2018.

126. Zhao Y, Samal E and Srivastava D: Serum response factor regulates a muscle-specific microRNA that targets Hand2 during cardiogenesis. Nature 436: 214-220, 2005.

127. Lu CX, Gong HR, Liu XY, Wang J, Zhao CM, Huang RT, Xue S and Yang YQ: A novel HAND2 loss-of-function mutation responsible for tetralogy of Fallot. Int J Mol Med 37 : 445-451, 2016

128. Ferreira LR, Frade AF, Santos RH, Teixeira PC, Baron MA, Navarro IC, Benvenuti LA, Fiorelli AI, Bocchi EA, Stolf NA, et al: MicroRNAs miR-1, miR-133a, miR-133b, miR-208a and miR-208b are dysregulated in chronic chagas disease cardiomyopathy. Int J Cardiol 175: 409-417, 2014.

129. Chen W and Li S: Circulating microRNA as a novel biomarker for pulmonary arterial hypertension due to congenital heart disease. Pediatr Cardiol 38: 86-94, 2017.

130. Patrick DM, Montgomery RL, Qi X, Obad S, Kauppinen S, Hill JA, van Rooij E and Olson EN: Stress-dependent cardiac remodeling occurs in the absence of microRNA-21 in mice. J Clin Invest 120: 3912-3916, 2010

131. Wang Y, Gu J, Roth JA, Hildebrandt MA, Lippman SM, Ye Y, Minna JD and Wu X: Pathway-based serum microRNA profiling and survival in patients with advanced-stage non-small cell lung cancer. Cancer Res 73: 4801-4809, 2013.

132. Hamam R, Hamam D, Alsaleh KA, Kassem M, Zaher W, Alfayez M, Aldahmash A and Alajez NM: Circulating microRNAs in breast cancer: Novel diagnostic and prognostic biomarkers. Cell Death Dis 8: e3045, 2017.

133. Duttagupta R, Jiang R, Gollub J, Getts RC and Jones KW: Impact of cellular miRNAs on circulating miRNA biomarker signatures. PLos One 6: e20769, 2011

134. Sassi Y, Avramopoulos P, Ramanujam D, Grüter L, Werfel S, Giosele S, Brunner AD, Esfandyari D, Papadopoulou AS, De Strooper B, et al: Cardiac myocyte miR-29 promotes pathological remodeling of the heart by activating Wnt signaling. Nat Commun 8: 1614, 2017.

This work is licensed under a Creative Commons Attribution-NonCommercial-NoDerivatives 4.0 International (CC BY-NC-ND 4.0) License. 